Zonage climatologique pour la culture des plantes fourragères dans la région de l'Atlantique

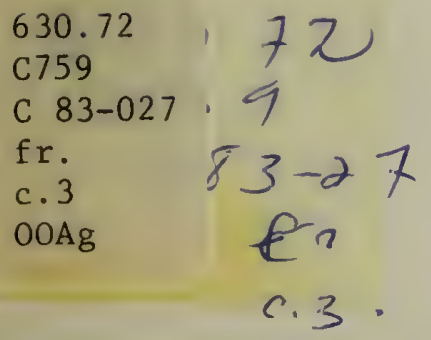


Sur la couverture, les points sur la carte indiquent

les établissements de recherche d'Agriculture Canada. 


\section{Zonage climatologique pour la culture des plantes fourragères dans la région de l'Atlantique}

\section{A. BOOTSMA}

Section d'agrométéorologie

Institut de recherche sur les terres

Ottawa (Ontario)

Contribution de l'I.R.T. n ${ }^{\circ} 83-01$

Direction générale de la recherche Agriculture Canada

1984 
On peut se procurer des exemplaires

de ce bulletin en s'adressant à:

A. Bootsma

Section d'agrométéorologie

Institut de recherche sur les terres

Direction générale de la recherche, Agriculture Canada

Ottawa (Ontario)

KlA 0 C6

Production du Service aux programmes de recherche

@Ministre des Approvisionnements et Services Canada 1984

Also available in English under the title

Climatic zonation for forage crops in the Atlantic Region 
TABLE DES MATIËRES

Page

REMERCIEMENTS

RESUME, SUMMARY

$\mathrm{v}$

1. INTRODUCTION

2. MÉTHODES

2.1 Estimation des dates de maturation pour la première récolte

2.2 Estimation de la période critique automnale défavorable à la récolte de la luzerne

2.3 Critère de zonage au point de vue de la fréquence des récoltes et du rendement potentiel

2.4 Critères de zonage au point de vue de l'indice de séchage et du déficit en eau

2.5 Préparation des cartes

3. RESULTATS ET COMMENTAIRES

3.1 Zonage en fonction des unités calorifiques permettant d'estimer la date optimale de première récolte

3.2 Période critique automnale défavorable à la récolte de la luzerne

3.3 Zonage en fonction de la fréquence des récoltes et du rendement potentiel

3.4 Zonage en fonction de l'indice de séchage et du déficit en ea $u$

4. CONCLUSION

5. REFERENCES

6. ANNEXE 


\section{LISTE DES TABLEAUX}

Page

\section{Tableau}

1. Valeur approximative du nombre de degrés-jours nécessaires à quelques plantes fourragères pour parvenir à certains stades de maturation.

2. Équations servant au calcul du déficit en eau (D.E.) résultant de la perte d'eau potentielle accumulée (P.E.P.A.).

3. Dates moyennes où un certain nombre de degrés-jours de croissance (D.J.C.) sont accumulés dans les zones de maturation de la figure 5.

4. Période critique automnale défavorable à la récolte de la luzerne dans les zones de la figure 6 .

5. Critère pour estimer la longueur de la saison de croissance dans les zones de la figure 7 .

6. Valeur approximative de la fréquence de récolte optimale pour diverses espèces de plantes fourragères dans les zones de la figure 7 .

7. Valeur moyenne approximative du rendement potentiel en matière sèche de plusieurs espèces fourragères dans les zones de la figure 7 .

8. Variation des indices de séchage des zones de la figure 8.

9. Variation de la perte d'eau potentielle accumulée (P.E.P.A.) et du déficit en ea dans les zones de la figure 9.

10. Comparaison qualitative entre les zones délimitées en fonction du déficit en eau, les classes d'humidité de la carte des conditions climatologiques des sols du Canada et des effets d'une pénurie d'eau sur deux espèces de plantes fourragères.

11. Liste des stations climatologiques utilisées pour l'étude de zonage et les données obtenues. 
Figure

1. Facteur de correction du nombre mensuel de degrés-jours de croissance au-dessus de $5^{\circ} \mathrm{C}$ (D.J.C.) au printemps.

2. Facteur de correction du nombre mensuel de degrés-jours de croissance au-dessus de $5^{\circ} \mathrm{C}$ (D.J.C.) en automne.

3. Relation entre le déficit en eau (méthode de Thornthwaite) et la perte d'eau potentielle accumulée pour trois valeurs de capacité de rétention spécifique.

4. Carte générale du territoire étudié dans la région de l'At lantique.

5. Zones de maturité pour la première coupe des cultures fourragères.

6. Périodes critiques de récolte de luzerne à l'automne.

7. Indices de croissance pour la fréquence de coupe et les rendements potentiels des cultures fourragères.

8. Indices d'assèchement pour la fenaison.

9. Zones de déficit hydrique pour les cultures fourragères.

10. Localisation approximative des stations météorologiques utilisées dans le cadre de l'étude de zonage concernant les cultures fourragères. 


\section{REMERCIEMENTS}

L'étude du climat de la région de l'Atlantique présentée dans les pages suivantes s'inscrit dans un projet qui vise à délimiter les différentes zones climatiques dans cette région pour faciliter l'élaboration de recommandations sur la régie et la production des cultures fourragères. Dans l'accomplissement de notre tâche, nous avons considérablement profité des conseils d'un comité spécial sur le zonage des terres à plantes fourragères de la région de l'Atlantique réunissant $M$. Suzuki, de la Station de recherche de Charlottetown, J. MacMillan, du ministère de l'Agriculture et du Développement Rural du Nouveau-Brunswick, et nous-mêmes. Nous remercions en outre les membres des Comités consultatifs des provinces de l'Atlantique sur les fourrages et sur l'agrométéorologie pour l'aide précieuse qu'ils nous ont apportée par leurs commentaires. Mentionnons également J. Dumanski, de l'Institut de recherche sur les terres, W.J. Blackburn et J.A. Dyer, de la Division de la production végétale (Direction générale du développement régional), et enfin M. Suzuki, qui ont bien voulu revoir le brouillon du présent compte rendu.

D. Grimmett, de la Station de recherche de Charlottetown, nous a donné de précieux conseils sur le traitement informatisé des données. Le personnel de la section d'agrométéorologie de l'Institut de recherche sur les terres nous a aussi assisté pour le traitement des données. Certaines des analyses préliminaires ont été réalisées avec l'aide de D.B. Walker et G.S. Rodd lorsque nous étions à l'emploi du ministère de l'Agriculture et de la Foresterie de l'lle-du-Prince-Édouard. Enfin, remercions les membres du service de copie de l'Institut de recherche sur les terres ainsi que ceux du service de cartographie. 


\section{RÉSUMÉ}

Dans le présent compte rendu, nous décrivons la variation en fonction de l'espace de plusieurs paramètres climatiques influant sur la production et la régie des cultures fourragères dans les provinces de l'Atlantique. D'après le nombre total de degrés-jours de croissance au-dessus de $5^{\circ} \mathrm{C}$ (D.J.C.) accumulés au printemps, on a estimé à quel moment les cultures de plusieurs espèces fourragères sont parvenues au stade de maturation crucial pour la première récolte. Les D.J.C. qui restent en automne indiquent la variation probable de la période critique automnale durant laquelle la luzerne et certaines autres espèces sensibles au froid d'hiver ne devraient pas être récoltées. La longueur de la période entre la date au printemps où un nombre précis de D.J.C. sont accumulés et la date en automne où un nombre précis de D.J.C. restent à venir sert de critère pour déterminer la variation de la fréquence appropriée des récoltes de plantes fourragères. Pour décrire les variations régionales des conditions de fenaison et des risques de pénurie d'eau durant l'été, on se sert de critères d'humidité simplifiés, basé sur l'abondance des précipitations et la valeur approximative de l'évapotranspiration potentielle.

\section{SUMMARY}

This bulletin describes the spatial variation of several derived climatic parameters of importance to forage crop production and management in the Atlantic Provinces. Accumulated growing degree-days above $5^{\circ} \mathrm{C}$ (GDD) in spring are used to estimate important maturity stages in several forage species for first cut. GDD's remaining in the fall are used to indicate probable variation in the critical fall period during which alfalfa and possibly other species susceptible to winterkill should not be harvested. The length of season between specified GDD's accumulated in spring and remaining in fall is used as a criterion for designating variation in suitable cutting frequencies of forages. Simplified moisture criteria based on rainfall and estimated potential evapotranspiration are used to describe regional differences in hay-making conditions and in the likelihood of moisture stress during summer months. 



\section{INTRODUCTION}

On a commandé l'étude dont nous rendons compte ici parce qu'il était nécessaire de délimiter les différentes zones climatiques de la région de l'Atlantique pour faire des recommandations précises sur la production et la régie des cultures fourragères dans cette région. En effet, le climat influe considérablement sur l'adaptabilité de diverses espèces et cultivars de plantes fourragères aux conditions de cette région. Les conditions climatiques permettent de cultiver une très grande variété de plantes fourragères, selon les avis du Comité de grandes cultures de l'Atlantique (A.F.C.C., 1980). La fléole est la plus répandue des graminées fourragères, mais d'autres espèces, comme la dactyle et le brome, sont également cultivées. On produit aussi des légumineuses comme la luzerne, le trèfle et le lotier, bien que le succès des récoltes dépende de la résistance des plantes aux rigueurs de l'hiver. Ces dernières années, l'ivraie annuelle a aussi gagné en popularité comme plante fourragère. De nombreux facteurs influent sur la production et la régie des cultures fourragères; le climat compte parmi les plus importants. Les conditions climatiques influent non seulement sur la croissance, la persistance, la qualité et le rendement des plantes, mais elles déterminent aussi la réaction de chacun des cultivars aux mesures culturales appliquées.

Nous nous sommes attachés à étudier quatre grands points sur lesquels les conditions climatiques exercent une influence considérable: (i) le moment où les cultures sont parvenues au stade de maturation le plus approprié pour faire la première récolte; (ii) la période critique automnale durant laquelle la bonne régie des cultures commande de ne pas récolter la luzerne; (iii) la fréquence des récoltes et le rendement des cultures fourragères selon la longueur de la saison de production et enfin (iv) les conditions de fenaison et les déficits en ea du sol en été.

(i) Le moment où les cultures fourragères parviennent à un certain stade de maturation est un facteur important dans la production de plantes fourragères de bonne qualité dans la région de l'Atlantique. Les recherches ont montré que les graminées doivent être récoltées au début de la production d'épis et les légumineuses doivent être moissonnées, au plus tard, à la première floraison pour que leur teneur en éléments nutritifs digestibles soit maximum (A.F.C.C., 1980). Les études ont également révélé qu'on peut étendre la récolte de la fléole en employant des cultivars à taux de croissance différents, ce qui permet de moissonner les cultures à leur stade de maturation optimal (Grant et Burgess, 1978). Pour un cultivar donné, le stade de maturation approprié pour la récolte varie essentiellement en fonction des conditions climatiques de la région de culture. Nous avons estimé la date moyenne où certains cultivars de luzerne, de fléole et de trèfle rouge atteignent le stade de maturation approprié pour la première récolte d'après le nombre total de degrés-jours de croissance au-dessus de $5^{\circ} \mathrm{C}$ accumulés (D.J.C.) dans chaque zone.

(ii) Nous avons aússi étudié la variation probable de la période critique automnale durant laquelle la luzerne ne devrait pas être récoltée. Dans bien des régions de l'Amérique du Nord, il faut laisser cette plante s'endurcir en automne afin qu'elle survive a ux rigueurs de l'hiver. 
Pendant environ six semaines en automne, il vaut mieux ne pas moissonner les cultures de luzerne ni y laisser paitre des bêtes, car la défoliation empêche l'endurcissement des plantes et augmente les risques de dommages au cours de l'hiver (Fulkerson, 1974; Gottfred, 1980; Heinrichs, 1969; Woolley et Wilsie, 1961). Cette période d'endurcissement varie selon les conditions climatiques. Fulkerson (1970) a constaté que dans les différentes régions du sud de l'Ontario, c'est au moment où les risques de gel atteignent $25 \%$ que la récolte réduit le plus la productivité de la luzerne. Le Comité de recherche sur les récoltes de grandes cultures de l'Ontario recommande aux agriculteurs de l'Ontario de ne pas moissonner la luzerne pendant une période de six semaines dont cette date critique constitue la médiane (O.F.C.R.C., 1981). Woolley et Wilsie (1961) doutaient de la validité de la date de récolte automnale déterminée d'après celle du premier gel destructeur et ont proposé en remplacement d'employer une méthode de totalisation des unités de froid basée sur la mesure de la température du sol pour déterminer la durée de la période d'endurcissement. Dans la région de l'Atlantique, on a constaté que la luzerne récoltée ou broutée l'automne précédent subissait plus de dommage durant l'hiver (MacKenzie et Suzuki, 1978; Suzuki et Mc Rae, 1979; Willis et Suzuki, 1971). Bien que des mesures culturales judicieuses ne soient pas une garantie que les cultures survivront à l'hiver, elle réduit néanmoins les risques de dommage. Par conséquent, selon les recommandations du Comité des grandes cultures de l'Atlantique, on ne devrait pas moissonner la luzerne ou y mettre des animaux en pâturage entre le $1^{\text {er }}$ septembre et le 15 octobre (A.F.C.C., 1980). Nous avons déterminé la période automnale critique durant laquelle il vaut mieux ne pas récolter la luzerne d'après le total de D.J.C. qui restent en automne. Cette méthode nous a semblé valable, car dans certaines autres régions, on a constaté que la période critique est plus hâtive là où la température baisse plus tôt en automne (Fulkerson, 1970; Woolley et Wilsie, 1961).

(iii) La fréquence des récoltes et le rendement potentiel de plusieurs espèces de plantes fourragères sont estimés selon le nombre de jours entre le moment, au printemps, où il s'est accumulé 350 D.J.C. et le moment, en automne, où il reste 450 D.J.C. Cette méthode est basée sur I'hypothèse selon laquelle la température est l'un des principaux facteurs limitants de la croissance au printemps et en automne, le développement des plantes durant l'été étant essentiellement une question de temps et dépendant moins de la température (en supposant qu'il n'y a aucune période de pénurie d'eau). Le rendement potentiel est défini ici comme le rendement qu'on peut obtenir grâce à une régie judicieuse mettant en application les moyens technologiques actuelles; on l'estime d'après les rendements mesurés lors d'essais effectués aux stations de recherche de la région les années où une assez bonne proportion des cultures ont survécu aux rigueurs de l'hiver.

(iv) Dans la région de l'Atlantique, les pluies sont généralement suffisantes pour les cultures en été. Certaines années toutefois, la pénurie d'eau retarde dans une mesure significative la croissance des plantes fourragères (A.F.C.C., 1975; Black, 1978; Calder et Nicholson, 1970). C'est le repousse qui suit la défoliation en été qui est le plus souvent 
perturbée, car la pénurie d'eau frappe le plus souvent durant cette période. Par exemple, durant l'été de 1975 dans l'lle-du-Prince-Édouard, on n'a pu faire de seconde récolte de fléole à cause de la sécheresse; la productivité de la deuxième récolte de luzerne a diminué d'au moins 50\% (A.F.C.C., 1975). Certaines années ou dans certaines régions, I'humidité excessive en été peut aussi avoir des conséquences néfastes pour les plantes fourragères. Black (1978) a constaté que l'excès d'humidité a provoqué une baisse de production des pâturages, peut-être à cause de l'engorgement du terrain et du lessivage des éléments nutritifs. Bien plus, I'humidité excessive durant la fenaison peut abaisser considérablement la qualité du foin en obligeant les agriculteurs à reporter la récolte après le stade de maturation optimal. Le temps pluvieux après la coupe entraîne aussi une baisse considérable de la quantité et de la qualité des fourrages (Wilkinson, 1981). Les constatations présentées ci-dessus confirment qu'il est important de considérer le taux d'humidité en été pour délimiter les zones de culture des plantes fourragères. Nous avons étudié la variation spatiale de l'indice de séchage du foin et du déficit en eau du sol d'après l'estimation de l'évapotranspiration potentielle et de l'abondance des pluies du début de juin à la fin d'août. Le déficit en eau dépend du climat (pluie, évaporation), du sol (capacité de rétention d'eau, drainage) et des plantes cultivées (transpiration, enracinement, résistance à la sécheresse). Comme la relation entre ces différents facteurs dans la région de l'Atlantique est encore mal connue, nous avons basé nos analyses sur des hypothèses simplifiées.

Dans le présent compte rendu, nous avons décrit en détail les méthodes que nous avons employées pour évaluer la distribution spatiale des paramètres climatiques jugés importants du point de vue de la culture des plantes fourragères; nous présentons également les résultats de nos analyses. Ces renseignements devraient s'avérer utiles aux agronomes chargés de formuler des recommandations sur la production et la régie des cultures fourragères dans la région de l'Atlantique. Nos résultats sont également importants pour évaluer les terres et pour estimer leur productivité potentielle. Pour tirer le meilleur parti possible de notre travail, il faut intégrer les données sur le climat et sur les sols de la région.

\section{MÉTHODES}

\subsection{Estimation des dates de maturation pour la première récolte}

Il existe très peu de renseignements sur les méthodes qui permettent de prévoir le stade de maturation d'une culture fourragère, même si l'on a beaucoup étudié l'influence de la température sur la croissance des graminées et des légumineuses (Knight et Hollowell, 1958; Kozumplik et Christie, 1972; Pearson et Hunt, 1972; Smith et Jewiss, 1966). La plupart des études ont montré que le développement jusqu'à maturité s'accélère avec la température, sauf lorsque celle-ci est extrêmement élevée. Des facteurs comme l'humidité, la fertilité et la longueur du jour peuvent influencer le taux de croissance jusqu'à un certain point. Cependant, vu le temps frais et humide qu'il fait habituellement au printemps dans la région de l'Atlantique, la température est le principal facteur qui détermine à quel moment les plantes parviennent à un 
certain stade de maturation. Selirio et Brown (1979) ont utilisé une valeur de 550 D.J.C. accumulés pour estimer à quel moment la luzerne fleurit dans le sud de l'Ontario. Si l'on compare les D.J.C. accumulés et les stades de maturation des cultures observés durant les essais effectués par le comité consultatif sur les cultures fourragères aux provinces de l'Atlantique, on constate que dans cette région, le début de la floraison des cultivars de luzerne Saranac et Iroquois, les années qui suivent l'ensemencement, se produit après l'accumulation d'environ 450 D.J.C. (Bootsma, observations inédites). Les cultivars de luzerne comme le Saranac croissent plus rapidement au printemps que les cultivars moyens tels que l'Iroquois, mais la plupart des cultivars parviennent à maturité à peu près au même moment. Les données indiquent aussi que la moitié des plants de fléole champ ont produit des épis après l'accumulation d'environ 450 D.J.C. Le cultivar de fléole Clair atteint ce stade quelque 50 à 70 degrés-jours avant le Champ, tandis qu'avec le Climax, il faut environ 50 à 70 degrés-jours de plus. Pour la région de l'Atlantique, on recommande les cultivars de fléole clair, champ et Climax de maturation très hâtive, hâtive et moyenne, respectivement. Les cultivars de trèfle rouge à double récolte ottawa et Lakeland atteignent le stade du début de la floraison au bout d'environ 450 D.J.C.

L'importante variation dans les degrés-jours nécessaires d'une saison à l'autre et d'un endroit à l'autre montre qu'il y aurait lieu de mettre au point une meilleure méthode pour prévoir les stades de maturation. Par exemple, pour atteindre le stade du début de la floraison, la luzerne nécessite généralement moins d'unités calorifiques à Saint-Jean (Terre-Neuve) que dans des endroits plus chauds dans les Maritimes. Certaines années et dans certains endroits, il y a plus de variation dans les dates de maturité et dans les besoins en degrés-jours entre les variétés que d'autres années et qu'en d'autres endroits. Comme nous n'avions pas d'autre méthode, nous avons employé les valeurs de degrés-jours accumulés qui figurent au tableau 1 pour estimer le stade de maturation de la fléole, de la luzerne et du trèfle rouge au printemps. Il pourra être nécessaire de les ajuster en fonction des nouveaux résultats qu'on obtiendra dans les parcelles expérimentales.

On a estimé les dates moyennes où les stades de maturation indiqués au tableaul sont atteints dans la région de l'Atlantique en déterminant la date moyenne où 350 et 450 D.J.C. s'étaient accumulés; on a utilisé les équations de régression quadratiques suivantes:

$$
\begin{aligned}
& Y_{1}=126,72-12,527 x_{1}+0,3077 x_{1}^{2} \\
& Y_{2}=140,11-13,201 x_{1}+0,3354 x_{1}^{2}
\end{aligned}
$$

où $\mathrm{Y}_{1}$ et $\mathrm{Y}_{2}$ représentent les dates moyennes auxquelles se sont accumulés

350 et 450 D.J.C. au printemps ( 1 er juin =1);

$\mathrm{x}_{1}$ est la température ambiante moyenne en mai et juin $\left({ }^{\circ} \mathrm{C}\right)$.

Nous avons appliqué les valeurs normales de température de 1951 à 1980 (Environnement Canada, 1982) à ces équations pour estimer $\mathrm{Y}_{1}$ et $\mathrm{Y}_{2}$ à 
Tableau 1 Valeur approximative du nombre de degrés-jours nécessaires à quelques plantes fourragères pour parvenir à certains stades de maturation

Nombre total

de degrés-jours

de croissance

au-dessus de

$5^{\circ} \mathrm{C}$ (D.J.C.)
Moment approximatif du stade de maturité au cours des années suivant l'ensemencement

\begin{tabular}{lllll}
\hline & trèfle & & fléole & \\
luzerne* & rouge & & \\
\cline { 3 - 4 } & & Clair & Champ & Climax
\end{tabular}

\begin{tabular}{|c|c|c|c|c|c|}
\hline 350 & $\begin{array}{c}\text { début du } \\
\text { bourgeonnement }\end{array}$ & - & $\begin{array}{l}\text { début de } \\
\text { l'épiaison }\end{array}$ & - & - \\
\hline 0 & $\begin{array}{l}\text { fin du } \\
\text { bourgeonnement }\end{array}$ & - & $\begin{array}{l}\text { épiaison } \\
\text { à } 50 \%\end{array}$ & $\begin{array}{l}\text { début de } \\
\text { l'épiaison }\end{array}$ & - \\
\hline & $\begin{array}{l}\text { début de } \\
\text { la floraison }\end{array}$ & $\begin{array}{l}\text { début de } \\
\text { la floraison }\end{array}$ & $\begin{array}{l}\text { épiaison } \\
\text { complète }\end{array}$ & $\begin{array}{l}\text { épiaison } \\
\text { à } 50 \%\end{array}$ & $\begin{array}{l}\text { début de } \\
\text { l'épiaison }\end{array}$ \\
\hline & - & - & - & $\begin{array}{l}\text { épiaison } \\
\text { complète }\end{array}$ & $\begin{array}{l}\text { épiaison } \\
\text { à } 50 \%\end{array}$ \\
\hline
\end{tabular}

* Moyenne établie d'après les cultivars Saranac et Iroquois.

* Moyenne établie d'après les cultivars Lakeland et ottawa.

231 stations météorologiques de la région de l'Atlantique. Les valeurs normales de température pour les stations en service depuis moins de 20 ans avaient été ajustées par Environnement Canada pour correspondre à la période normale de 30 ans au moyen de techniques standard.

Nous avons déterminé les équations (1) et (2) par des analyses de régression linéaire multiple appliquées aux données relevées dans 68 stations météorologiques de la région de l'Atlantique pendant la période normale de 1941 à 1970 (Environnement Canada, 1971). Dans les deux cas, le coefficient de détermination $\left(r^{2}\right)$ était de 0,984 et l'erreur-type (e.-t.) de $l$ 'estimation était de $<1$ jour. Pour développer les équations, nous avons déterminé le nombre de D.J.C. accumulés d'après la courbe de la température ambiante moyenne de chaque mois à chaque station en additionnant les D.J.C. de chaque jour. Pour les mois totalisant moins de 200 D.J.C., nous avons appliqué l'équation de régression suivante pour corriger les sommations de D.J.C. fondées sur les graphiques:

$$
Y_{C}=19,98+0,904 Y_{G}
$$

où $\mathrm{Y}_{C}$ représente la somme des D.J.C. mensuels avec correction et

$\mathrm{Y}_{\mathrm{G}}$ représente la somme des $\mathrm{D}$.J.C. mensuels établie d'après la courbe de la température moyenne.

Nous avons développé l'équation (3) en appliquant à $Y_{C}$ les valeurs mensuelles de D.J.C. publiées par Environnement Canada (Treidl, 1978), car elles ont été calculées d'après les températures ambiantes quotidiennes 
maximums et minimums. Avec les données de 23 stations-mois, le $\mathrm{r}^{2}$ était de 0,99 et $l$ 'e.-t. était de 6,5 D.J.C. Il s'est avéré que la correction des sommations de D.J.C. établies d'après la température ambiante moyenne était aussi précise tout en étant plus simple que la méthode de Thom (1966). Nous avons aussi appliqué un facteur de correction (figure 1) pour les mois où il n'y a eu aucun D.J.C. d'accumulé, mais où la température moyenne était supérieure à $1^{\circ} \mathrm{C}$. La figure 1 a été mise au point en comparant la valeur mensuelle moyenne de la température ambiante avec le nombre de D.J.C. mesurés par Environnement Canada dans le cas des stations-mois pour lesquelles le nombre de D.J.C. établis au moyen de la courbe était nul.

Nous avons fait une autre vérification de l'exactitude de la méthode graphique avec corrections pour déterminer les dates d'accumulation de 350 D.J.C. et de 450 D.J.C. en comparant les résultats obtenus avec les données d'Environnement Canada (Treidl, 1979) pour 36 emplacements. Nous nous sommes servis des sommes hebdomadaires de D.J.C. d'Environnement Canada pour déterminer par interpolation les dates où se sont accumulés 350 et 450 D. J.C. Les résultats que nous obtenus avec ces deux méthodes étaient en étroite corrélation $(r=0,996)$ et l'écart n'était généralement que d'un jour au plus, ce qui indique que la courbe était suffisamment précise pour nos besoins.

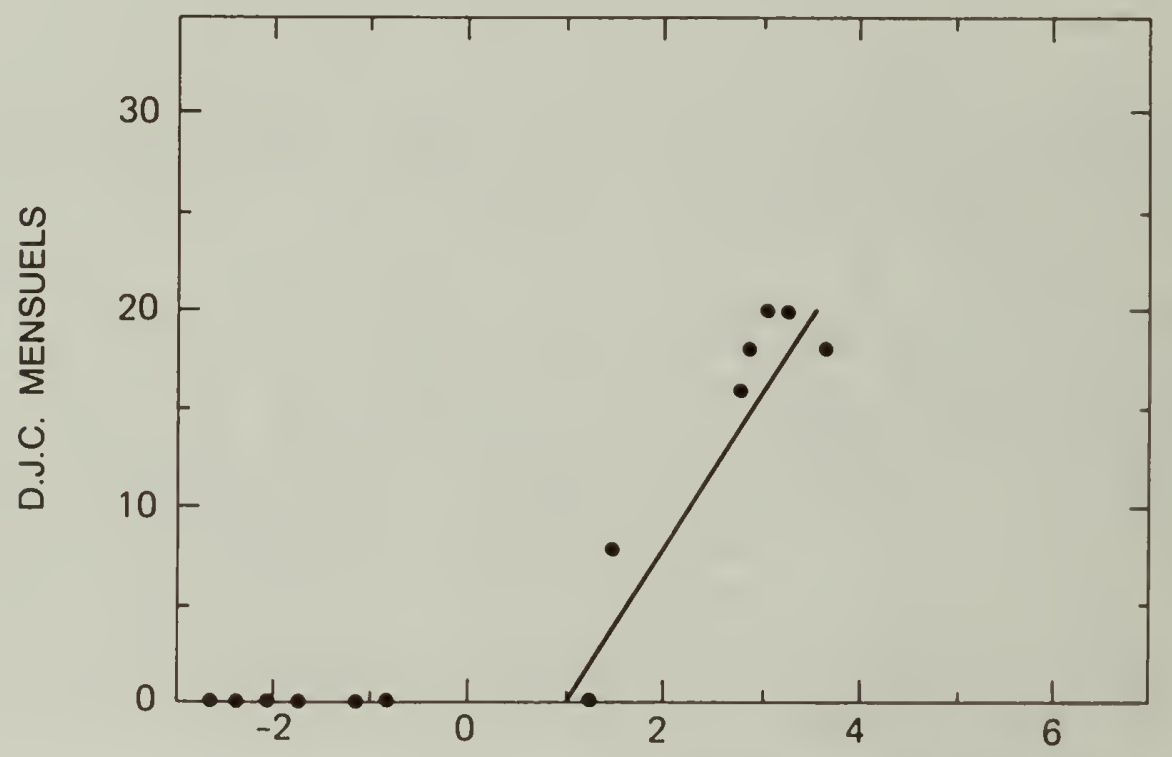

MOYENNE MENSUELLE DE LA TEMPÉRATURE AMBIANTE $\left({ }^{\circ} \mathrm{C}\right)$

Figure 1 Facteur de correction du nombre mensuel de degrés-jours de croissance au-dessus de $5^{\circ} \mathrm{C}$ (D.J.C.) au printemps 


\subsection{Estimation de la période critique automnale défavorable à la récolte de la luzerne}

La période critique automnale durant laquelle la luzerne ne devrait pas être récoltée était définie comme la période de 45 jours commençant le jour où il reste encore une moyenne de $450 \mathrm{D} . J . C$. en automne. Cette définition a été jugée correcte, car on a constaté que les périodes ainsi déterminées coincidaient avec la période critique actuellement délimitée dans la région de l'Atlantique par le Comité des grandes cultures de l'Atlantique (A.F.C.C., 1980) pour les endroits où l'on a régulièrement fait des essais de culture de luzerne sur le terrain (Charlottetown, Nappan, Truro). De plus, la date médiane des périodes ainsi définies correspondait presque à celle où les risques de gel atteignent 25\% dans les terres intérieures du Nouvea u-Brunswick et de la Nouvelle-Écosse, ce qui concorde étroitement avec la relation qui existe entre la date critique de récolte (a u milieu de la période critique de récolte) et les risques de gel en Ontario (Fulkerson, 1970). Dans les régions côtières, la date médiane de cette période était considérablement plus avancée que celle où les risques de gel étaient de $25 \%$ et ce, à cause de l'effet modérateur de la mer sur les températures nocturnes. Il pourrait plus tard devenir nécessaire de modifier cette définition pour rendre compte des nouveaux renseignements sur l'effet de la régie des récoltes sur la survie a ux rigueurs de l'hiver dans la région de l'Atlantique.

Pour calculer la date moyenne à laquelle il reste 450 D.J.C. en automne, nous nous sommes servis de la même méthode que pour estimer le nombre de D.J.C. au printemps. Les valeurs normales de température, mesurées de 1951 à 1980 (Environnement Canada, 1982) dans 232 stations météorologiques, ont été appliquées dans l'équation de régression suivante:

$$
Y_{3}=-43,34+6,317 X
$$

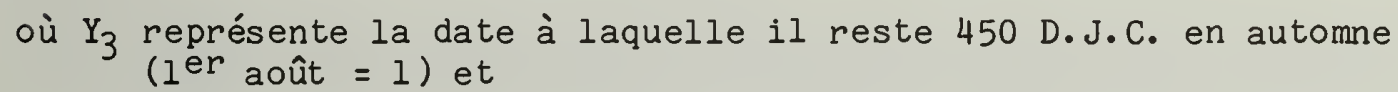

$\mathrm{X}$ est la température ambiante moyenne des mois de septembre et d'octobre $\left({ }^{\circ} \mathrm{C}\right)$.

Nous avons déterminé l'équation (4) par l'analyse de régression linéaire de données recueillies dans 68 stations de la région de l'Atlantique durant la période normale allant de 1941 à 1970 (Environnement Canada, 1971). Le $r^{2}$ s'élevait à 0,98 et l'e.-t. était d'un jour. Nous avons fait des essais avec diverses combinaisons de températures moyennes et de termes quadratiques, mais la précision de la fonction de régression ne s'en est pas trouvé améliorée de façon significative. La date à laquelle il reste 450 D.J.C. ( $Y_{3}$ ) a été déterminée d'après les courbes de température normale; on a totalisé le nombre de D.J.C. pour chaque jour en remontant dans le temps depuis la date à laquelle la courbe de la température moyenne est descendue en dessous de $5^{\circ} \mathrm{C}$. Pour corriger ces sommations, nous avons employé les mêmes méthodes qu'avec les données concernant le printemps. Pour corriger les sommations des mois durant lesquels il s'est accumulé moins de 220 D.J.C., nous nous sommes servis de l'équation de régression suivante: 


$$
Y_{C}=24,03+0,894 X_{G}
$$

où $Y_{C}$ représente la sommation des D.J.C. mensuels avec correction et

$\mathrm{Y}_{\mathrm{G}}$ représente le nombre de D.J.C. mensuels établi d'après la courbe de la température moyenne.

Pour déterminer l'équation (5), nous avons appliqué à $\mathrm{Y}_{C}$ les sommes de D.J.C. mensuels publiées par Environnement Canada (Treidl, 1978) de la même façon qu'avec l'équation (3) pour le printemps. Avec les données de 26 stations-mois, la valeur de $r^{2}$ était de 0,99 et l'e.-t. était de 6,2 D.J.C. On peut voir à la figure 2 le facteur de correction employé pour les mois où le nombre de D.J.C. était nul d'après la courbe de la température moyenne, mais durant lesquels la température moyenne était supérieure à $0^{\circ} \mathrm{C}$. Cette figure est semblable à la figure 1 (données de printemps).

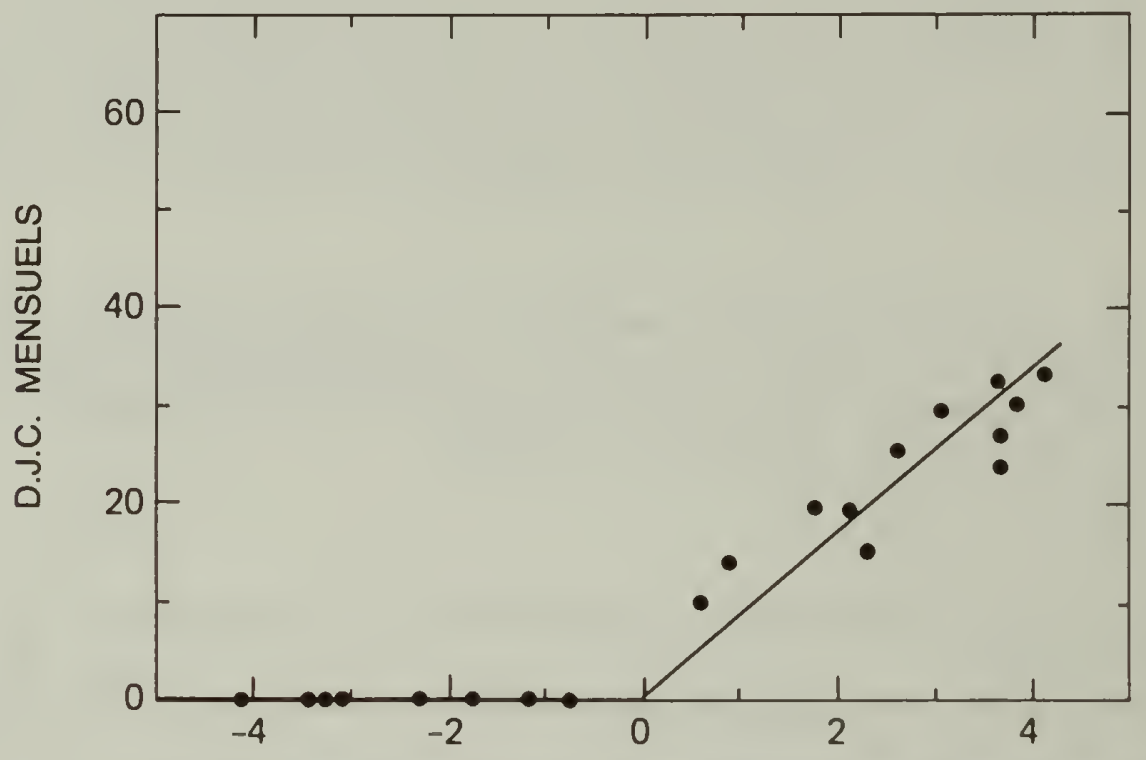

MOYENNE MENSUELLE DE LA TEMPÉRATURE AMBIANTE $\left({ }^{\circ} \mathrm{C}\right)$

Figure 2 Facteur de correction du nombre mensuel de degrés-jours de croissance a videssus de $5^{\circ} \mathrm{C}$ (D.J.C.) en automne

Nous avons évalué la précision de la méthode graphique pour estimer la date à laquelle il reste 450 D.J.C. en automne, en comparant nos résultats avec les dates établies par interpolation des sommes hebdomadaires de D.J.C. publiées par Environnement Canada (Treidl, 1979) pour 36 stations. Nous avons supposé que les dates établies d'après les données d'Environnement Canada étaient correctes, puisque les sommes de D.J.C. étaient basées sur les valeurs maximum et minimum de la température ambiante quotidienne. Avec la méthode graphique, les dates établies après correction étaient généralement de 1 à 3 jours plus avancées que celles déterminées d'après les données d'Environnement Canada. La relation entre les dates établies par ces deux méthodes s'exprime par l'équation de régression suivante: 


$$
\mathrm{Y}_{\mathrm{A}}=2,96+0,954 \mathrm{X}_{\mathrm{G}}
$$

où $\mathrm{Y}_{\mathrm{A}}$ représente la date à laquelle il reste 450 D.J.C. en automne d'après les données d'Environnement Canada et

$\mathrm{X}_{\mathrm{G}}$ est la date déterminée au moyen des courbes de température normale avec correction.

Pour l'équation (6), le $r^{2}$ s'élevait à 0,97 et l'e.-t. était de 1,3 jour. Nous avons ajusté la date approximative où seraient accumulés 450 D.J.C. en automne dans les 232 stations de la région en appliquant la valeur de $Y_{3}$ déterminée dans l'équation (4) à $X_{G}$ dans l'équation (6). Ces valeurs ajustées constituent le premier jour de la période de 45 jours durant laquelle la luzerne ne devrait pas être récoltée.

\subsection{Critère de zonage au point de vue de la fréquence des récoltes et du rendement potentiel}

Dans les parties 2.1 et 2.2 , nous avons décrit les méthodes que nous avons employées pour estimer la date où il s'est accumulé 350 D.J.C. au printemps et celle où il reste 450 D.J.C. en automne durant une année moyenne. Nous nous sommes servis du nombre de jours entre ces deux dates (JOURS) comme critère de zonage a li point de vue de la fréquence des récoltes et du rendement potentiel d'un certain nombre d'espèces fourragères. Nous avons partiellement expliqué nos raisons dans l'introduction. Dans chaque région, les plantes fourragères vivaces disposent pour leur croissance du nombre de jours indiqués par ce paramètre auquel s'ajoute un supplément de 800 D.J.C. (au printemps et en automne). Dans le cas de la luzerne, le paramètre JouRS représente la période de croissance des cultivars hâtifs après la première récolte; elle dure jusqu'à la période critique automnale, durant laquelle il vaut mieux ne pas récolter.

\subsection{Critère de zonage au point de vue de l'indice de séchage et du déficit en $\underline{\text { eau }}$}

Les possibilités relatives de séchage du foin dans les champs des diverses parties de la région de l'Atlantique ont été évaluées au moyen d'un indice de séchage mis au point par Hayhoe et Jackson (1974) d'après des expériences sur le terrain. Cet indice est défini par la formule suivante:

$$
I=E P-0,2 P
$$

où EP représente l'évaporation potentielle ( $\mathrm{mm}$ )

$P$ représente les précipitations $(\mathrm{mm})$

I est la valeur de l'indice.

L'équation (7) permet de déterminer la valeur de l'indice I pour un jour ou un certain nombre de jours. Pour les besoins de notre étude, nous avons déterminé l'indice cumulatif des mois de juin à août pour plus de 230 stations au moyen des valeurs normales de la température et des précipitations pendant la période normale allant de 1951 à 1980 (Environnement Canada, 1982). Nous avons estimé l'évaporation potentielle totale au moyen de l'équation de Baier et Robertson (1965) en appliquant le facteur de conversion de Baier (1971) tel qu'indiqué dans les lignes suivantes. 
La valeur moyenne de l'évaporation latente quotidienne (EL), exprimée en $\mathrm{cm}^{3}$, a été déterminée pour la période allant de juin à août avec l'équation suivante:

$$
\mathrm{EL}=-57,334+1,6704 \mathrm{TMAX}+1,6794 \mathrm{TRANGE}+0,0486 \mathrm{Q}
$$

où TMAX est la valeur moyenne de la température quotidienne maximum de juin à août $\left({ }^{\circ} \mathrm{C}\right)$

TRANGE est la différence moyenne, en ${ }^{\circ} \mathrm{C}$, entre le maximum et le minimum de la température quotidienne durant la même période

Qo est la valeur moyenne du rayonnement solaire total dans le haut de l'atmosphère durant la même période (cal. $\mathrm{cm}^{-2}$ jour ${ }^{-1}$ ).

Nous avons estimé la valeur de $Q_{0}$ d'après la latitude (LAT) de la station au moyen des formules suivantes:

$$
Q_{0}=934,4+3,6308(52,0-\operatorname{LAT}) 0,927
$$

lorsque la station se situait entre $43^{\circ}$ et $51,5^{\circ}$ de latitude Nord, et

$$
Q_{0}=907,3+4,1759(59,0-\text { LAT }) 0,970
$$

lorsque la station se situait à plus de $51,5^{\circ}$ mais à moins de $59^{\circ}$ de latitude Nord.

Pour développer les équations (9) et (10), nous avons calculé Qo pour des latitudes données en appliquant la valeur du rayonnement solaire quotidien dans le haut de l'atmosphère déterminée selon la méthode de Robertson et Russelo (1968). La valeur de $r^{2}$ dépassait 0,99 pour ces deux équations.

Les valeurs de EL établies avec l'équation (8) ont été converties en EP totale (mm), pour les mois de juin à août au moyen de la formule suivante:

$$
\text { EP totale }=E L \times 0,086 \times \mathrm{N}
$$

où $\mathrm{N}$ est le nombre total de jours dans cette période.

Pour des raisons d'ordre pratique, nous avons normalisé l'indice de séchage I à une valeur maximum de 100 au moyen de la formule suivante:

$$
I_{N}=\frac{I}{I_{M A X}} \times 100
$$

où $I_{N}$ est l'indice normalisé

I est l'indice de séchage initial établi avec l'équation (7) et

$I_{M A X}$ est la valeur maximum de l'indice de séchage; on considère que c'est $360 \mathrm{~mm}$.

Le zonage en fonction des déficits en ea $u$ a été établi selon une version modifiée des méthodes décrites en détails par Thornthwaite (1948) et Thornthwaite et Mather (1957) pour établir le bilan hydrique. Thornthwaite définit le déficit en eau comme la valeur d'évapotranspiration théorique qui 
dépasse l'évapotranspiration réelle, un mois donné. Cette méthode comporte de longs calculs et nécessite que l'on connaisse la valeur de la capacité de rétention spécifique (C.R.S.).

Nous avons calculé le déficit en eau pour trois valeurs de C.R.S. (50, 100 et $200 \mathrm{~mm}$ ) en appliquant les relations entre déficit saisonnier en eau et perte d'ea u potentielle accumulée (P.E.P.A.) de la figure 3. Thornthwaite et Mather (1957) ont défini la P.E.P.A. comme la somme de toutes les valeurs mensuelles négatives de $P$ - EP. Pour des raisons d'ordre pratique, nous avons préféré définir la P.E.P.A. comme la somme de toutes les valeurs positives de $E P$ - P. Les relations illustrées à la figure 3 ont été établies d'après les valeurs du bilan hydrique (méthode de Thornthwaite) établies par Phillips (1976) pour un certain nombre de stations de l'Ontario et des provinces de l'Atlantique. Toutefois, Phillips n'a évalué le déficit en eau que pour les C.R.S. de 100 et de $200 \mathrm{~mm}$. La courbe correspondant à la C.R.S. de $50 \mathrm{~mm}$ a été établie d'après le déficit en eau qu'on obtient avec les méthodes de Thornthwaite (Thornthwaite et Mather, 1957).

Nous avons calculé la P.E.P.A. pour 232 stations météorologiques de la région de l'Atlantique en appliquant les valeurs des précipitations totales et de EP totale pour les mois de juin à août de la période normale de 1951 à 1980 (Environnement Canada, 1982). Notre méthode était valable, car dans la plupart des cas la valeur de EP - P était positive ou presque nulle pour ces mois seulement. Pour estimer la valeur de EP, nous avons appliqué la méthode décrite pour le calcul de l'indice de séchage plutôt que celle de Thornthwaite. Avec cette dernière, la valeur de EP est surestimée dans les zones côtières de la région de l'Atlantique parce qu'elle est basée sur la température moyenne et qu'elle ne tient pas compte des différences d'humidité relative ou d'un déficit de pression de vapeur. La formule de Baier et Robertson (1965) rend compte, jusqu'à un certain point, des différences d'humidité, car les zones côtières de température moyenne comparable à celle des zones situées dans les terres ont une valeur de EP plus faible du fait que la variation nycthémérale de la température est moins grande. Pour certaines stations, les EP déterminées selon la formule de Baier et Robertson dépassaient, par une valeur pouvant aller jusqu'à 20\%, celles obtenues par la méthode de Thornthwaite. Dans ce cas, par conséquent, nous avons employé les données de stations ontariennes (Phillips, 1976) pour déterminer la relation entre les valeurs de P.E.P.A. et de déficit en eau présentées à la figure 3.

Nous avons calculé les déficits en eau à partir des équations ajustées aux courbes de la figure 3. C'est en appliquant deux équations à chacune des courbes que nous avons obtenu les meilleurs résultats, comme on le montre au tableau 2.

\subsection{Préparation des cartes}

Les critères décrits dans les pages précédentes ont été appliqués à environ 232 stations météorologiques de la région de l'Atlantique. Les résultats ont été inscrits sur des cartes de la région et des isolignes reliant les points d'égale valeur ont été tracées en tenant compte des grands traits topographiques comme la vallée d'Annapolis et la vallée de la rivière Saint-Jean. Nous avons utilisé les données de certaines stations météorologiques du Québec et du Maine pour établir, au voisinage des 
Tableau 2 Équations servant au calcul du déficit en eau (D.E.) résultant de la perte d'ea u potentielle accumulée (P.E.P.A.)

\begin{tabular}{|c|c|c|}
\hline$\underset{(\mathrm{mm})}{\text { C. R.S. }}$ & $\begin{array}{l}\text { Varia- } \\
\text { tion des } \\
\text { P.E.P.A. } \\
(\mathrm{mm})\end{array}$ & Équation employée pour estimer le déficit en eau \\
\hline 50 & 0 à 70 & D.E. $=0,404+0,11351$ P.E.P.A. $+0,005220(\text { P.E.P.A. })^{2}$ \\
\hline 50 & $>70$ & D.E. $=-16,658+0,6520$ P.E.P.A. $+0,0010685(\text { P.E.P.A. })^{2}$ \\
\hline 100 & 0 à 150 & D.E. $=0,01697$ (P.E.P.A. $)^{1,67581}$ \\
\hline 100 & $>150$ & D.E. $=0,85338$ P.E.P.A. $-52,776$ \\
\hline 200 & 0 à 150 & D.E. $=0,0061224$ (P.E.P.A. $)^{1,78276}$ \\
\hline 200 & $>150$ & D.E. $=0,61737$ P.E.P.A. $-46,222$ \\
\hline
\end{tabular}

\footnotetext{
* I C.R.S. - capacité de rétention spécifique.

*2 P.E.P.A. - perte d'ea u potentielle accumulée.

Nota: Si P.E.P.A. $\leq 0,0$, alors D.E. $=0,0$.
}

frontières, la position des isolignes des paramètres décrits en 2.1 , 2.2 et 2.3. Nous avons en outre procédé à certains ajustements pour corriger l'erreur que comporte la mesure de ces paramètres dans les stations synoptiques horaires de premier ordre de la région. Ces erreurs viennent de ce que la journée météorologique, d'après laquelle on détermine la température minimum, est différente selon qu'il s'agit d'une station synoptique ou d'une station ordinaire (Bootsma, 1976). Par exemple, si dans les stations horaires la valeur mensuelle de la température ambiante moyenne comporte une erreur, la date de maturation printanière estimée (partie 2.1) peut être repoussée d'une valeur pouvant aller jusqu'à 5 jours. Pour l'élaboration de la carte, lorsque les différences étaient évidentes, nous avons donné plus d'importance aux stations météorologiques ordinaires qu'aux stations de premier ordre.

\section{RESULTATS ET COMMENTAIRES}

La figure 4 représente une carte générale de la région de l'Atlantique sur laquelle sont indiqués les lieux mentionnés dans le texte. La province de Terre-Neuve est représentée à une échelle considérablement plus petite que les trois autres provinces des Maritimes. L'Annexe contient la liste des stations météorologiques dont nous avons employé les résultats, et les valeurs des critères indiqués, que nous avons obtenues d'après les calculs. A la figure 10 de l'Annexe, on donne l'emplacement approximatif des stations météorologiques. 


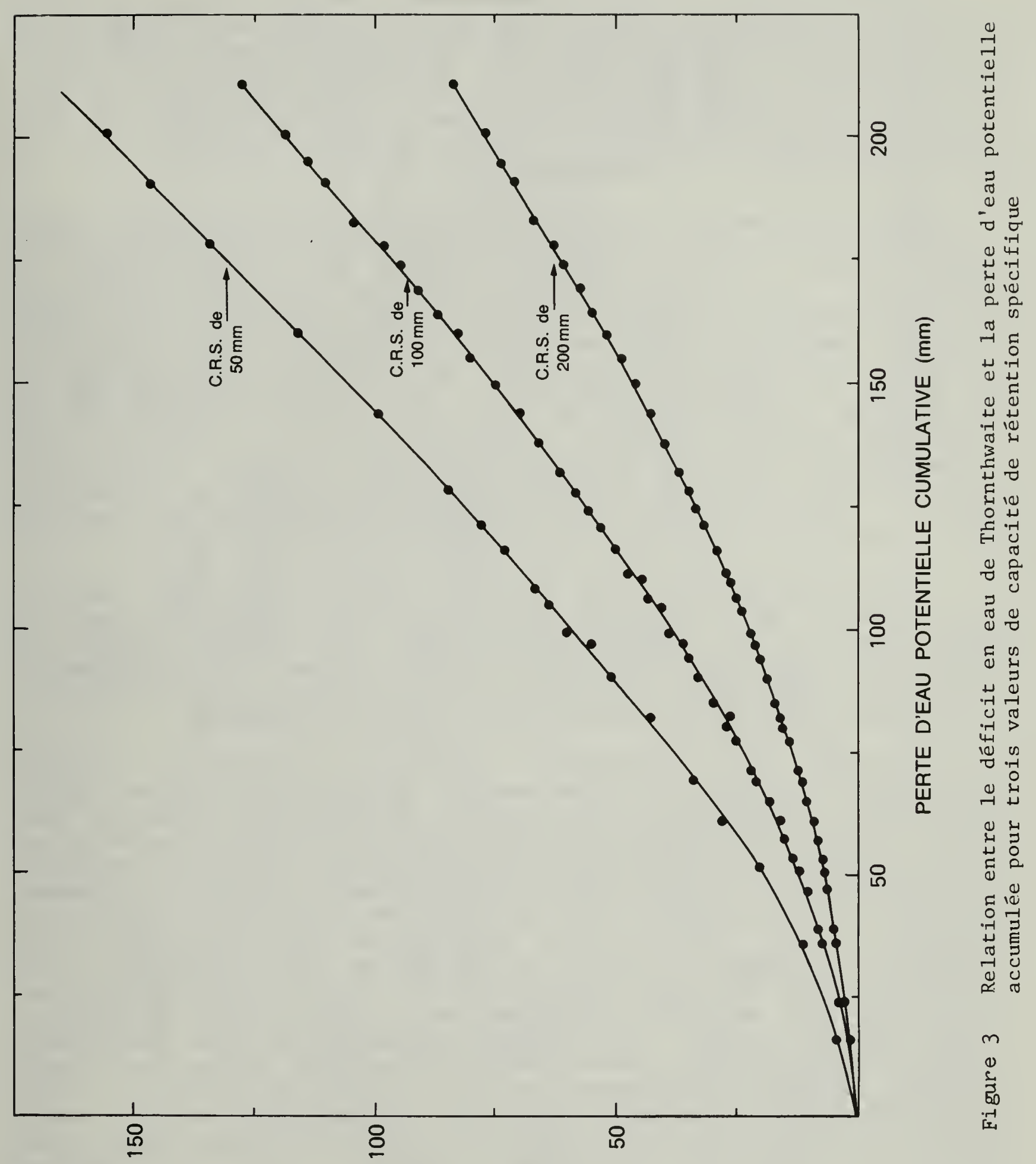

DÉFICIT HYDRIQUE (mm) 


\subsection{Zonage en fonction des unités calorifiques permettant d'estimer la date optimale de première récolte}

Constatant qu'il y avait correspondance entre les isolignes établies d'après les équations (1) et (2) pour les dates où se sont accumulés 350 D.J.C. et 450 D.J.C. au printemps, nous n'avons tracé qu'une carte de zonage pour l'ensemble de la région (figure 5). En général, les 450 D.J.C. étaient atteints 10 jours après la date où 350 D.J.C. s'étaient accumulés. On donne au tableau 3 la date moyenne d'accumulation de 350,400 et 450 D.J.C. dans chacune des zones de la figure 5. Les dates où 400 D.J.C. se sont accumulés ont été déterminées par interpolation.

La date d'accumulation de 350 D.J.C. au printemps varie beaucoup: avant le 15 juin dans la vallée d'Annapolis et la vallée de la rivière Saint-Jean et aussi tard que la dernière semaine de juillet dans certaines parties de Terre-Neuve. On estime que lorsque 350 D.J.C. sont accumulés, les cultivars de luzerne Saranac et Iroquois atteignent le stade du début du bourgeonnement au cours d'une année moyenne dans chacune des régions. C'est le moment le plus tôt possible pour faire une première moisson si l'on veut bénéficier de la période de régénération maximum pour faire d'autres récoltes dans la saison. La luzerne récoltée à cette date serait plus digestible et contiendrait plus de protéines que celle récoltée à la date où $450 \mathrm{D}$.J.C. sont accumulés, mais la récolte serait moins importante en termes de quantité de matière sèche, d'après le comité des grandes cultures de l'Atlantique (A.F.C.C., 1980). On présume que la fléole Clair aurait également atteint le stade de maturation approprié pour la première récolte à cette date.

La date d'accumulation de 450 D.J.C. au printemps varie aussi: avant le 25 juin dans la vallée d'Annapolis et la vallée de la rivière Saint-Jean, et aussi tard que la première semaine d'août dans certaines régions de Terre-Neuve. C'est approximativement la date optimale pour la première récolte de la fléole Climax et des cultivars de trèfle rouge à double récolte; c'est aussi la date la plus tardive pour la récolte de la luzerne.

Nos données sont établies en fonction de l'accumulation d'unités calorifiques prévue pour les années normales. La date de maturité peut varier d'une saison à l'autre selon les conditions météorologiques. Dans une même zone, le nombre d'unités calorifiques peut aussi varier selon la nature du sol et les différences du microclimat. Par exemple, les plantes fourragères cultivées dans un sol frais et humide qui se réchauffe lentement au printemps parviennent à maturité plus tard que celles des terrains plus chauds; les rendements peuvent cependant être plus élevés dans le premier cas. L'exposition du champ de culture aux intempéries influe également sur la quantité d'unités calorifiques accumulées; ainsi, dans les lieux protégés par des brise-vent ou des accidents géographiques, la date de maturité peut être considérablement avancée. Les stations météorologiques sont généralement situées à des emplacements assez exposés aux intempéries, si bien que la carte de zonage représente probablement assez bien ce genre de conditions. Cette carte devrait être utile pour formuler des recommandations quant au moment approprié de faire la première récolte des plantes fourragères dans chaque zone de la région de l'Atlantique. Toutefois, comme les conditions environnementales locales et les méthodes de culture influent sur la maturation des plantes, les agriculteurs devront faire des observations sur place pour déterminer à quel moment il est vraiment approprié de procéder à la première récolte. 


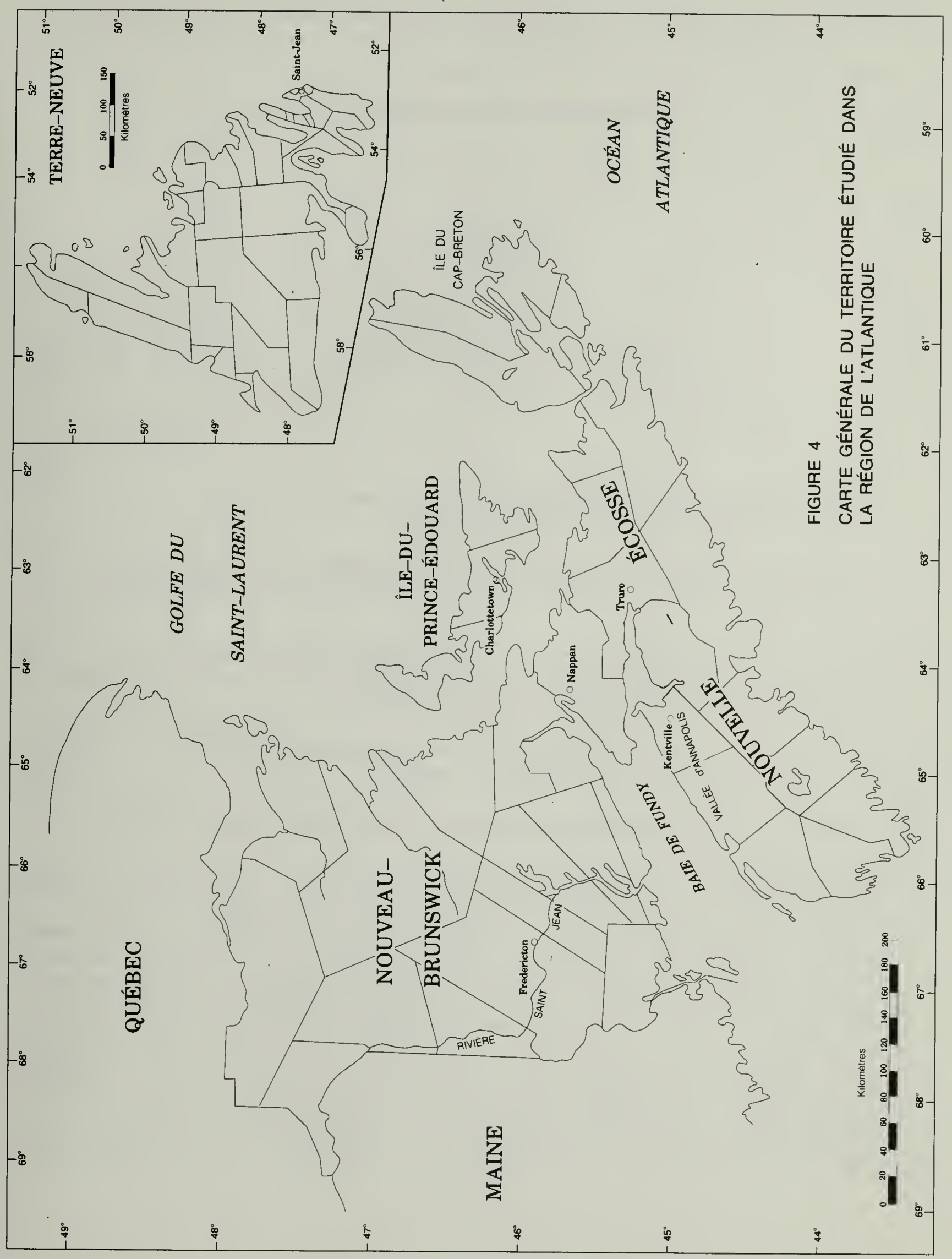


Tableau 3 Dates moyennes où un certain nombre de degrés-jours de croissance (D.J.C.) sont accumulés pour les zones de maturation de la figure 5

\begin{tabular}{|c|c|c|c|}
\hline \multirow{2}{*}{ Zone } & \multicolumn{3}{|c|}{ Date moyenne d'accumulation des D.J.C. } \\
\hline & 350 D.J.C. ${ }^{* 1}$ & 400 D.J.C. ${ }^{* 2}$ & 450 D.J.C. $* 3$ \\
\hline Ml & $\begin{array}{l}15 \text { juin } \\
\text { ou plus tôt }\end{array}$ & $\begin{array}{l}21 \text { juin } \\
\text { ou plus tôt }\end{array}$ & $\begin{array}{l}25 \text { juin } \\
\text { ou plus tôt }\end{array}$ \\
\hline M2 & 16 au 20 juin & 22 au 26 juin & 26 au 30 juin \\
\hline $\begin{array}{l}\text { M3 } \\
\text { M4 }\end{array}$ & $\begin{array}{l}21 \text { au } 25 \text { juin } \\
26 \text { au } 30 \text { juin }\end{array}$ & $\begin{array}{l}27 \text { juin au } 1^{\text {er }} \text { juill. } \\
2 \text { au } 6 \text { juillet }\end{array}$ & $\begin{array}{l}\text { ler au } 5 \text { juillet } \\
6 \text { au } 10 \text { juillet }\end{array}$ \\
\hline M5 & $1^{\text {er }}$ au 5 juillet & 7 au 11 juillet & 11 au 15 juillet \\
\hline $\begin{array}{l}\text { M6 } \\
M 7\end{array}$ & $\begin{array}{l}6 \text { au } 15 \text { juillet } \\
16 \text { au } 25 \text { juillet }\end{array}$ & $\begin{array}{l}12 \text { au } 21 \text { juillet } \\
22 \text { au } 31 \text { juillet }\end{array}$ & $\begin{array}{l}16 \text { au } 25 \text { juillet } \\
26 \text { juill au } 4 \text { aoat }\end{array}$ \\
\hline M8 & $\begin{array}{l}26 \text { juillet } \\
\text { ou plus tard }\end{array}$ & $\begin{array}{l}\text { ler août } \\
\text { ou plus tard }\end{array}$ & $\begin{array}{l}5 \text { août } \\
\text { ou plus tard }\end{array}$ \\
\hline
\end{tabular}

* Date moyenne estimée du début du bourgeonnement de la luzerne et du début de l'épiaison de la fléole Clair.

*2 Date moyenne estimée de la fin du bourgeonnement de la luzerne, de l'épiaison à $50 \%$ de la fléole Clair et du début de l'épiaison de la fléole Champ.

*3 Date moyenne estimée du début de la floraison de la luzerne et du trèfle rouge à double récolte, de l'épiaison à $50 \%$ de la fléole Champ et du début de l'épiaison de la fléole Climax.

Nota: Par luzerne on entend les cultivars Saranac et Iroquois et par trèfle rouge, les cultivars Lakeland et ottawa.

\subsection{Période critique automnale défavorable à la récolte de la luzerne}

Nous avons employé la date moyenne à laquelle il reste 450 D.J.C. en automne, déterminée au moyen des équations (4) et (6), pour établir la carte de zonage présentée à la figure 6 . Étant donné que la date où il reste 450 D.J.C. est considérée comme le début de la période de 45 jours pendant laquelle il ne faut pas récolter la luzerne, nous avons pu définir la période critique automnale pour chaque zone; nos résultats sont présentés au tableau 4. Le premier jour de la période critique selon les estimations arrivait dès le 5 août, dans le nord-ouest du Nouveau-Brunswick, et seulement le 5 septembre, dans certaines régions côtières du sud-ouest de la Nouvelle-Écosse. Dans la plupart des zones agricoles de la région, le premier jour de la période critique tombait, selon les estimations, entre le 21 aoat et 1 e 4 septembre (zones F5 à F7). Au Labrador, il restait en automne 450 D.J.C. dès le 10 juillet dans le nord et ce jour n'arrivait qu'après le 25 juillet dans le sud-est. 


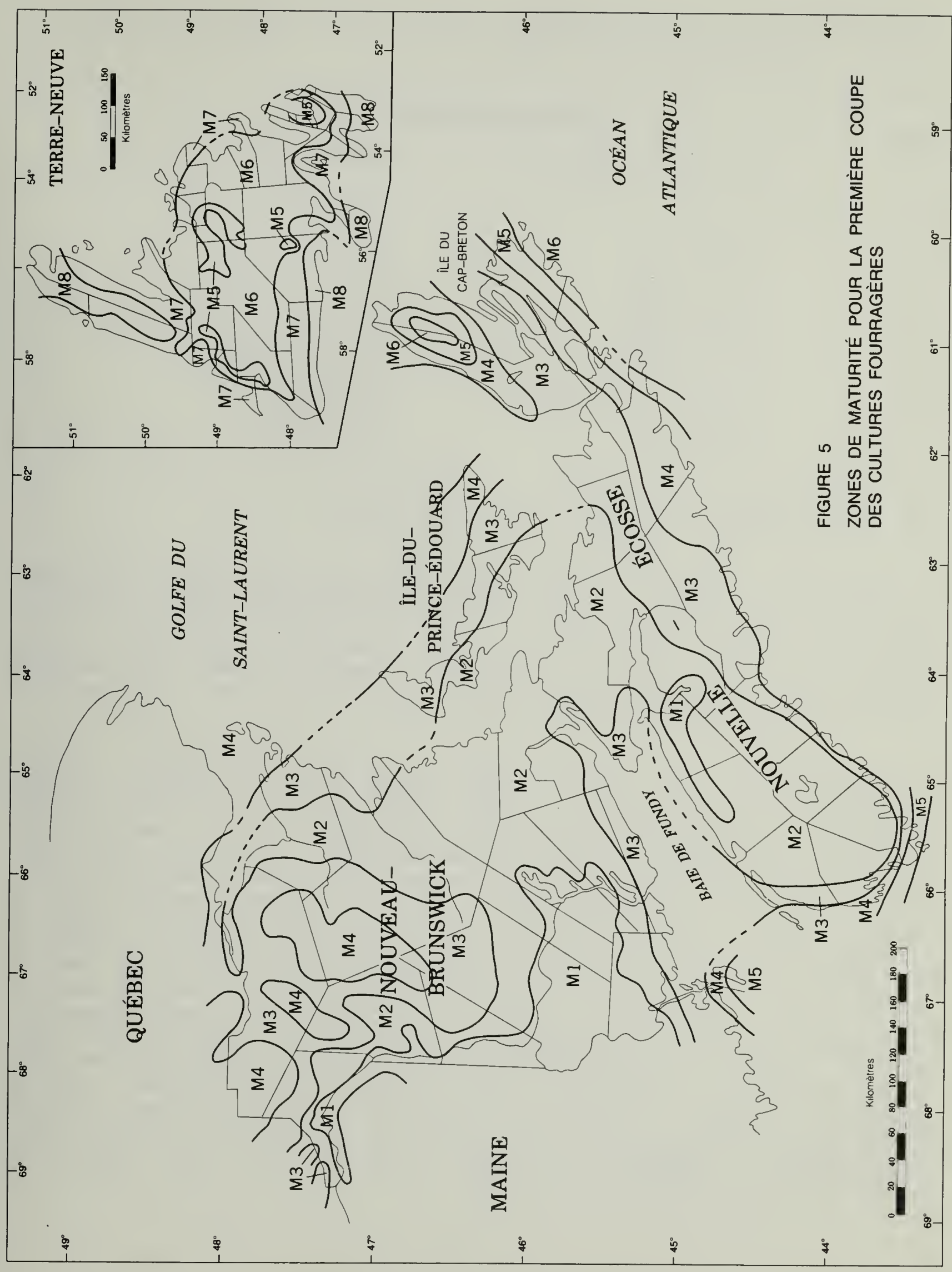


Tableau 4 Période critique automnale défavorable à la récolte de la luzerne dans les zones de la figure 6

Période critique automnale

Zone
Début de la période
*1
Fin de la période *2

$\begin{array}{ll}\text { F1 } & 5 \text { août } \\ \text { F2 } & \text { ou plus tôt } \\ \text { F3 } & 6 \text { au } 10 \text { août } \\ \text { F4 } & 11 \text { au } 15 \text { aôt } \\ \text { F5 } & 16 \text { au } 20 \text { aût } \\ \text { F6 } & 21 \text { au } 25 \text { août } \\ \text { F7 } & 26 \text { au } 30 \text { août } \\ \text { F8 } & 31 \text { août au } 4 \text { septembre } \\ & 5 \text { septembre } \\ & \text { ou plus tard }\end{array}$

20 septembre
ou plus tôt
21 au 25 septembre
26 au 30 septembre
1 er au 5 octobre
6 au 10 octobre
11 au 15 octobre
16 au 20 octobre
21 octobre
ou plus tard

* Date à laquelle il reste 450 D.J.C. en automne.

*2 45 jours après le début de la période.

La carte de zonage a été établie en fonction d'une échelle relativement étendue. Il est probable que la période critique défavorable à la récolte varie d'un endroit à l'autre dans une même zone, selon la protection contre les intempéries et l'exposition au gel. La période critique dans une zone donnée peut aussi varier d'une année à l'autre à cause des conditions météorologiques saisonnières, mais il est peu probable que cette variation soit importante (Fulkerson, 1970).

Dans les zones où il est possible de produire de la luzerne, il est préférable de ne pas récolter cette plante durant la période critique déterminée d'après la carte de zonage, car autrement les plantes ne peuvent s'endurcir suffisamment avant la dormance (Fulkerson, 1970). C'est au milieu de la période critique qu'il est le plus dommageable de faire la récolte, car les plantes doivent entrer alors en dormance lorsque leurs réserves nutritives sont au plus bas (Fulkerson, 1974). Dans les champs moissonnés avant la période critique, la croissance des plantes reprend et des bourgeons se forment sur les tiges de la base et sur le collet; durant ce stade de croissance tardive, il s'accumule suffisamment de réserves nutritives dans les racines. Les bourgeons doivent être bien protégés, car c'est de ceux qui auront survécu aux rigueurs de l'hiver que naitront les nouvelles pousses au printemps. En laissant sur place les parties de la plante qui ont poussé durant l'automne, on peut assurer aux bourgeons une protection accrue étant donné que la repousse ralentit le vent et retient la neige en hiver. Dans les champs où la luzerne résiste bien aux rigueurs de l'hiver, on peut raccourcir la période critique au début ou à la fin sans augmenter les pertes de façon significative. Néanmoins, une telle décision doit être fondée sur l'expérience des conditions locales. 


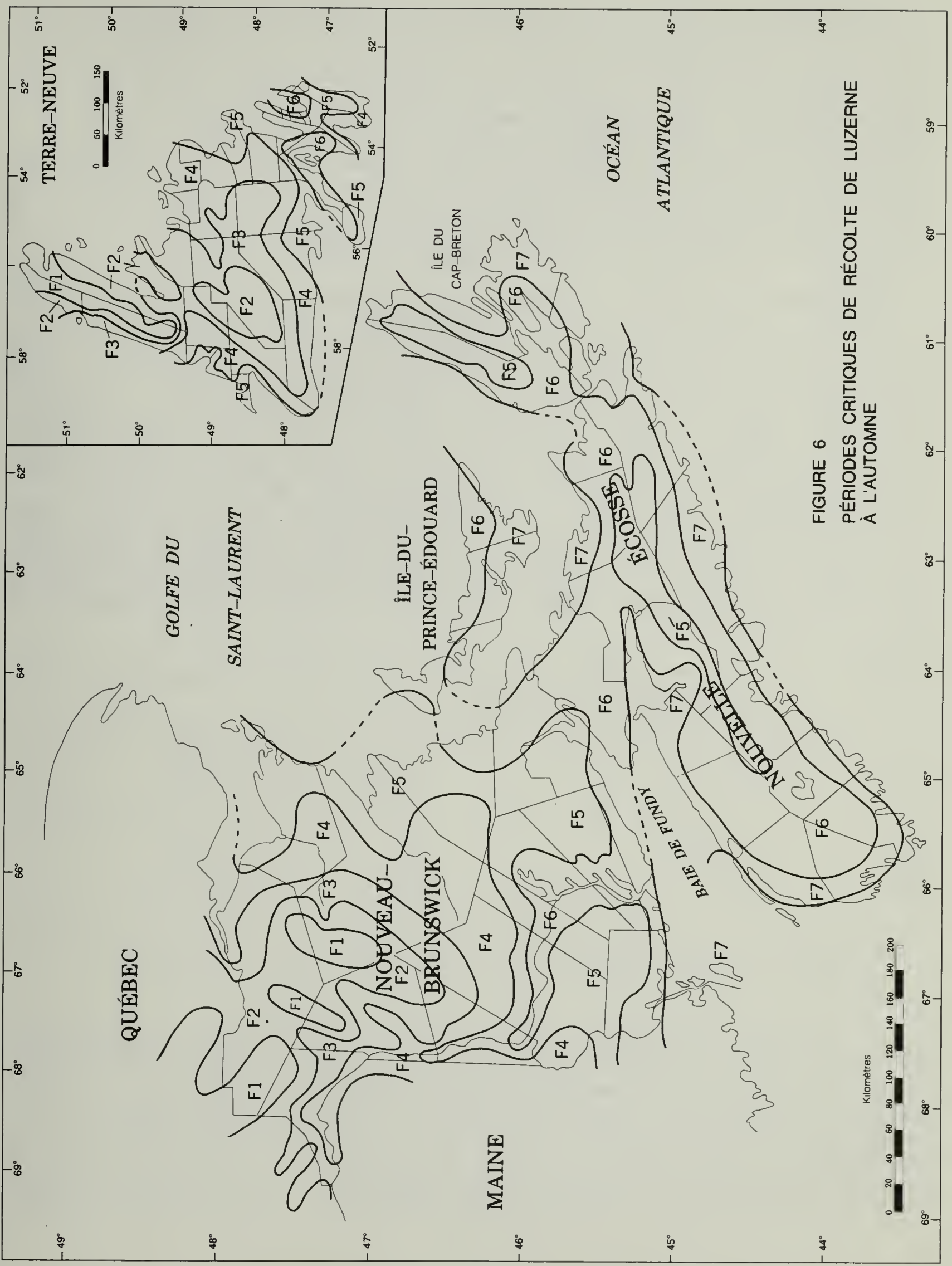


La carte de zonage devrait permettre de formuler des recommandations sur la régie de la récolte de la luzerne à la fin de l'été et en automne. Le fait de suivre les recommandations sur la récolte n'est pas une garantie qu'une bonne partie des plantes survivront à l'hiver, mais c'est un moyen de réduire les risques de pertes. La carte de zonage pourrait aussi se révéler utile pour la culture d'autres espèces sensibles au froid nécessitant une période de repos automnale. Par exemple, d'après les données expérimentales qu'on a recueillies en ontario, le lotier a besoin d'une période de repos automnale, mais dans son cas, la date critique susceptible de causer le plus de pertes arrive plus d'une semaine plus tôt que pour la luzerne (Fulkerson, 1982). La carte pourrait peut-être aussi servir pour la régie du trèfle et d'autres graminées moins résistantes comme le dactyle et l'ivraie vivace.

\subsection{Zonage en fonction de la fréquence des récoltes et du rendement potentiel}

La variation de l'indice de longueur de la saison de croissance (JOURS) dans la région est illustrée sur la carte de zonage de la figure 7 . On donne au tableau 5 la plage de variation de l'indice pour chaque zone. On voit que sa valeur dépasse 75 jours dans une partie de la vallée de la rivière Saint-Jean, dans la vallée d'Annapolis et dans une partie de la côte nord de la Nouvelle-Écosse. La plupart des autres grandes régions agricoles des Maritimes se trouvent dans la zone $\mathrm{H} 2$ pour laquelle l'indice se situe entre 60 et 74 jours. A Terre-Neuve, l'indice JOURS varie de moins de zéro, dans l'extrême nord, à plus de 45 jours, dans la région de la vallée Humber, dans le secteur délimité par Grand Falls et le lac Gander ainsi qu'aux environs de Saint-Jean. Au Labrador, la date à laquelle il s'est accumulé 350 D.J.C. au printemps tombe généralement entre 10 et 30 jours après celle oul il reste 450 D.J.C. en automne.

Tableau 5 Critère pour estimer la longueur de la saison de croissance dans les zones de la figure 7

$\begin{array}{llll}\text { H1 } & 75 \text { ou plus } & H 4 & 39 \text { à } 20 \\ \text { H2 } & 74 \text { à } 60 & \text { H5 } & 19 \text { à } 0 \\ \text { H3 } & 59 \text { à } 40 & H 6 & \text { moins de } 0\end{array}$

* A cette période de croissance s'ajoutent les 350 D.J.C. du printemps et les 450 D.J.C. de l'automne.

Afin d'évaluer le rendement potentiel et la fréquence de récolte optimale pour les diverses zones de la région, nous avons examiné les résultats des essais régionaux de cultivars réalisés de 1971 à 1981 par le comité consultatif sur les cultures fourragères (auparavant le sous-comité sur les plantes fourragères du Comité des grandes cultures de l'Atlantique) et des expériences sur le terrain de Kunelius et coll. (1976, 1977b, 1978, 1980) et de Macleod et coll. (1972). Comme les essais sur le terrain n'ont été réalisés que dans trois des six zones délimitées, les directives proposées sont un peu théoriques et devraient être vérifiées et, au besoin, ajustées 


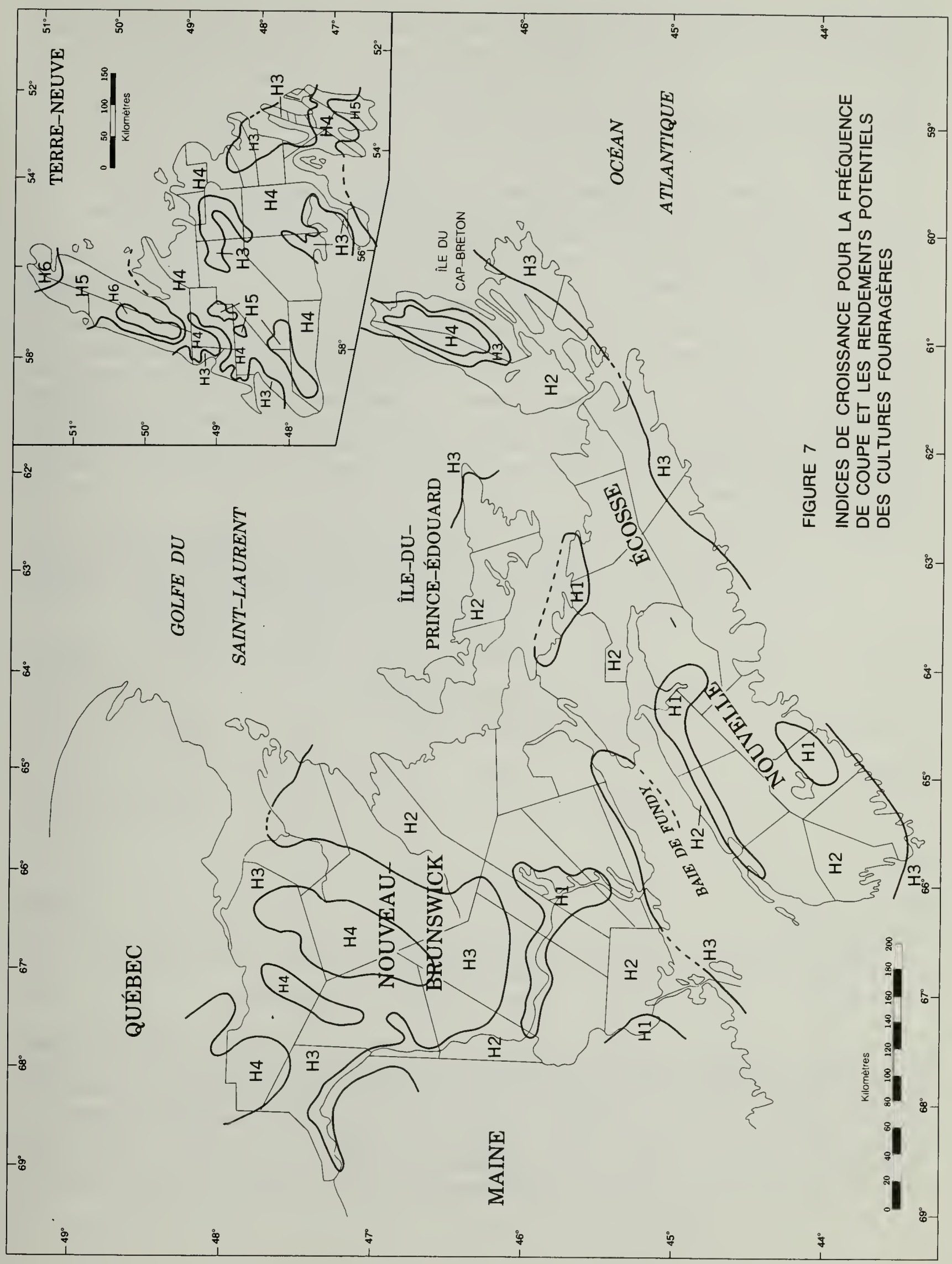


pour rendre compte des résultats des nouveaux essais ou de l'expérience acquise au cours des années. Les renseignements sur le trèfle rouge étaient plutôt rares, car pendant plusieurs années il a été difficile d'assurer la survie à l'hiver d'une quantité suffisante de plantes dans les parcelles expérimentales. On n'avait en outre que relativement peu de données sur le dactyle par comparaison avec la plupart des autres espèces de plantes fourragères.

On donne dans les tableaux 6 et 7 la fréquence de récolte optimale et le rendement potentiel de plusieurs espèces de plantes fourragères cultivées dans la région, pour chacune des zones de la figure 7. Le rendement potentiel est le reridement qu'on devrait obtenir en pratiquant une régie judicieuse avec les moyens techniques actuels. On estime cette valeur d'après le rendement obtenu au cours des essais sur le terrain effectués dans les stations de recherche les années où les plantes ont relativement bien résisté à l'hiver. Certaines années, les dommages dus au froid peuvent considérablement réduire le rendement des cultures de luzerne, de trèfle et de dactyle, si bien qu'il est difficile d'obtenir le rendement potentiel tous les ans. Nous avons établi les fréquences de récoltes que nous proposons en cherchant à équilibrer qualité et rendement. Souvent, la qualité des plantes fourragères est meilleure dans les cultures oul les récoltes sont plus fréquentes, mais le rendement et la persistance s'en trouvent diminués.

Tableau 6 Valeur approximative de la fréquence de récolte optimale pour diverses espèces de plantes fourragères dans les zones de la figure 7

Es pèce fourragère

Fréquence de récolte optimale

$\begin{array}{llllll}\mathrm{HI} & \mathrm{H} 2 & \mathrm{H} 3 & \mathrm{H} 4 & \mathrm{H} 5 & \mathrm{H} 6\end{array}$

Ivraie annuelle $e^{*}$

Luzerne

Dactyle

Fléole et brome

Trèfle rouge ${ }^{* 2}$
4

3

4 à 3

2

2
4 à 3

3 à 2

4 à 3

2

2
3 à 2

2

3

2

2 à 1
2

1

2

2

1
2 à 1

1 à 0

1

1

1

1

\footnotetext{
*I Fréquence pour l'année d'ensemencement; dans tous les autres cas, il s'agit des années suivant l'ensemencement.

*2 Cultivars à double récolte comme l'Ottawa et le Lakeland.
}

Comme on 1 'indique au tableau 6 , dans le cas de l'ivraie annuelle, on peut faire quatre récoltes dans les meilleures zones de production, soit Hl et H2, si l'on s'en tient à la fréquence optimale (Kunelius, 1980; Kunelius et Calder, 1978); il est cependant possible de faire une cinquième récolte. Le rendement potentiel varie de 8 tonnes (métriques) de matière sèche par hectare, dans les zones les plus productives, à moins de 5 tonnes par hectare, dans les zones où la saison de croissance est plus courte. L'ivraie annuelle 
gagne la faveur des cultivateurs de la région entre autres parce qu'elle assure un approvisionnement de fourrage de bonne qualité pour le bétail à la fin de l'automne, lorsque la plupart des graminées vivaces sont improductives (Kunelius, 1980; Kunelius et Calder, 1978).

Les fréquences de récolte qu'on propose pour la luzerne sont établies en supposant qu'il faut au moins 40 jours pour que la plante repousse après la première moisson et avant la période de repos automnale durant laquelle il vaut mieux ne pas récolter. Il n'est donc possible de faire qu'une récolte dans la zone $\mathrm{H} 4$, mais on peut en faire deux dans la zone H3. Dans les zones $\mathrm{HI}$ et $\mathrm{H} 2$, on peut faire deux autres récoltes avant la période de repos automnale. Il s'agit-là de directives générales qu'il faut ajuster selon les conditions locales. Par exemple, dans les lieux où les cultures persistent peu ou résistent mal aux rigueurs de l'hiver, il peut être nécessaire de réduire le nombre de récoltes, tandis que dans les terrains où les plantes résistent bien au froid, on peut faire une récolte supplémentaire à la fin de l'automne, après la période critique (Macleod et coll., 1972). Il peut être avantageux de faire moins de récoltes les années où la croissance est limitée par une période de froid ou de sécheresse inhabituelle. Dans les zones les plus productives ( $\mathrm{Hl}$, $\mathrm{H} 2$ et $\mathrm{H} 3$ ), on peut obtenir un rendement de 8,5 tonnes de matière sèche par hectare si les plantes sont régies de manière judicieuse, si les conditions météorologiques sont normales et si les plantes résistent bien aux rigueurs de l'hiver (tableau 7). Dans les zones H4 et H5, le rendement potentiel est réduit en partie parce qu'on ne peut faire qu'une seule récolte.

Tableau 7 Valeur moyenne approximative du rendement potentiel en matière sèche de plusieurs espèces fourragères, dans les zones de la figure 7

Espèce fourragère

Rendement potentiel moyen en matière sèche (tonnes métriques/ha)*1

\begin{tabular}{llllll}
\hline $\mathrm{H} I$ & $\mathrm{H} 2$ & $\mathrm{H} 3$ & $\mathrm{H} 4$ & $\mathrm{H} 5$ & $\mathrm{H} 6$
\end{tabular}

Ivraie annuelle*2

8,0

8,0

7,0

5,0

3,0

Luzerne

8,5

8,5

8,5

6,5

4,0

Dactyle

7,0

7,5

6,5

5,5

4,0

3,5

Brome

7,5

8,0

7,0

6,0

5,0

4,0

Fléole

8,5

9,0

9,0

8,0

6,0

5,0

Trèfle rouge 3

8,0

8,5

7,5

6,0

4,0

* Valeurs établies en supposant à peu près les mêmes fréquences de récolte qu'au tableau 6 .

*2 Rendement pour l'année d'ensemencement; dans tous les autres cas, il s'agit des années suivant l'ensemencement. 
Le dactyle est une plante vivace de saison fraîche à croissance rapide qu'on peut récolter trois ou quatre fois par saison dans les zones de la région les plus propices (Kunelius et Suzuki, 1977b). C'est toutefois une plante sensible au froid qui peut avoir besoin d'une longue période de repos automnal comme la luzerne (Kunelius et Suzuki, 1977a). Lorsque la survie aux rigueurs de l'hiver s'est révélée insuffisante, il peut être nécessaire de faire moins de récoltes que l'indique le tableau 6. Dans les zones les plus productives ( $\mathrm{HL}$ et $\mathrm{H} 2$ ), on peut obtenir en moyenne 7 tonnes de matière sèche par hectare ou plus; dans les zones $\mathrm{H} 5$ et $\mathrm{H} 6$, cependant, le rendement est limité à cause de la température peu élevée et de la courte durée de la saison de croissance des plantes.

La fléole est la principale plante fourragère dans la région; on peut obtenir 8 tonnes de matière sèche par hectare ou plus dans les zones $\mathrm{HI}$ à $\mathrm{H} 4$, si l'on emploi des pratiques culturales judicieuses. Dans ces zones, il est possible de faire deux moissons. Si l'on augmente le nombre de récoltes, le rendement s'en trouve réduit, mais le fourrage est de meilleure qualité (Kunelius et coll., 1976). Le brome se distingue parce que sa repousse est vigoureuse et que par temps sec il donne de meilleurs résultats que la fléole, mais il est un peu moins rustique que cette dernière. Il est possible de faire deux récoltes sauf dans les zones oul la saison de croissance est la plus courte (H5 et $\mathrm{H} 6$ ).

Dans les zones $\mathrm{Hl}$, $\mathrm{H} 2$ et $\mathrm{H3}$, on peut faire deux récoltes de trèfle rouge s'il s'agit de cultivars à floraison hâtive comme le Lakeland et l'ottawa. Dans les zones $\mathrm{H} 4$ et $\mathrm{H} 5$, on ne peut faire qu'une seule récolte, car la saison de croissance est plus courte. Les résultats des essais sur le terrain indiquent qu'on peut généralement procéder à la seconde récolte 50 jours ou plus après la reprise de croissance. Dans les zones climatiques les plus propices à la culture du trèfle rouge, on peut obtenir un rendement de 8,0 tonnes de matière sèche par hectare. Cependant, comme le trèfle rouge est une légumineuse à courte vie souvent détruite par le froid, il est plus utile pour les rotations à court terme (A.F.C.C., 1980). Par ailleurs, il convient moins bien que la plupart des autres espèces fourragères au fanage.

Ces directives générales sur la fréquence des récoltes et le rendement potentiel s'appliquent lorsque les conditions météorologiques sont près de la normale. Les années où ce n'est pas le cas, la fréquence optimale de récolte et le rendement peuvent s'en trouver affectés, pour la plupart des espèces. Le plus souvent, la fréquence des récoltes doit être déterminée en tenant compte d'un grand nombre de facteurs, notamment la qualité, le rendement, la persistance sur pied, la résistance aux rigueurs de l'hiver, les conditions météorologiques saisonnières et la forme d'entreposage (foin ou ensilage).

La carte de zonage que nous proposons (figure 7) devrait se révéler utile pour formuler des recommandations sur la fréquence de récolte et le rendement potentiel des plantes fourragères cultivées dans les diverses parties de la région. Il faudrait y apporter certaines améliorations pour rendre compte de l'effet de certains facteurs comme la résistance aux rigueurs de l'hiver, l 'humidité accessible aux plantes et la qualité du fourrage sur la fréquence optimale de récolte et le rendement potentiel. 


\subsection{Zonage en fonction de l'indice de séchage et du déficit en eau}

On présente à la figure 8 une carte de zonage sur laquelle sont indiquées les conditions de séchage relatives pour le fanage dans la région. Les zones ont été délimitées en fonction de diverses valeurs de l'indice de séchage normalisé choisies arbitrairement (tableau 8). Dans ce tableau on montre également la variation de l'indice de séchage et l'on donne une cote qualitative indiquant les conditions de fanage dans chaque zone. Il faudrait analyser de façon plus détaillée les conditions de séchage du foin en fonction du climat de chaque zone pour être en mesure de donner une évaluation plus quantitative des conditions de séchage. Néanmoins, nous donnons sur la carte actuelle une bonne idée des conditions relatives dans la région.

Tableau 8 Variation des indices de séchage des zones de la figure 8

\begin{tabular}{|c|c|c|c|}
\hline Zone & $\begin{array}{l}\text { Indice } \\
\text { de séchage } \\
(\mathrm{mm})\end{array}$ & $\begin{array}{l}\text { Indice } \\
\text { normalisé* }\end{array}$ & Conditions de fenaison \\
\hline Dl & $>325$ & $>90$ & $\begin{array}{l}\text { Passables à bonnes (conditions les } \\
\text { plus propices de la région) }\end{array}$ \\
\hline D2 & 290 à 325 & 80 à 90 & Passables \\
\hline D3 & 235 à 290 & 65 à 80 & Passables à mauvaises \\
\hline D4 & 180 à 235 & 50 à 65 & Mauvaises \\
\hline D5 & $<180$ & $<50$ & $\begin{array}{l}\text { Très mauvaises (potentiel de séchage } \\
\text { dans le champ le plus faiole de la } \\
\text { région) }\end{array}$ \\
\hline
\end{tabular}

*Indice normalisé $=\frac{\text { Indice de séchage }}{\text { Indice de séchage max. }} \times 100$

où 1 'indice de séchage max. vaut $360 \mathrm{~mm}$.

C'est dans la zone Dl que les conditions de séchage sont les meilleures; 1 'indice normalisé y est de 90 et la valeur réelle de l'indice de séchage est de $325 \mathrm{~mm}$. Cette zone comprend une longue portion de la vallée de la rivière Saint-Jean et couvre une grande partie de l'est du Nouveau-Brunswick. Elle touche aussi plusieurs régions de la Nouvelle-Écosse, notamment une partie de la vallée d'Annapolis, certaines terres au sud de Truro et une partie de la région côte nord, soit les principales régions agricoles de la province. L'Île-du-Prince-Édouard se trouve pour la plus grande partie dans la zone D3 où l'indice normalisé se situe entre 65 et 80 . Les conditions de séchage moins favorables dans cette province ne sont pas dues à des précipitations plus abondantes, mais plutôt à une réduction du facteur EP causée par une température diurne plus basse et une humidité plus élevée. Il en va de même pour la province de Terre-Neuve, dont la plus grande partie a un potentiel de séchage peu élevé (zones D3, D4 et D5) à cause d'un facteur EP faible plutôt que de l'abondance des précipitations. 
Par comparaison au facteur EP, la valeur des précipitations moyennes est relativement uniforme dans l'ensemble de la région de l'Atlantique, de juin à aout. En effet, dans la plus grande partie de cette région, il tombe en moyenne de 230 à $280 \mathrm{~mm}$ de pluie durant ces trois mois; par contre, le facteur EP varie de moins de $250 \mathrm{~mm}$ à plus de $400 \mathrm{~mm}$.

La carte de zonage nous donne une bonne idée des conditions de séchage relatives dans la région et devrait s'avérer utile, avec un complément de renseignements sur les conditions de fenaison dans chaque zone, pour formuler des recommandations sur les méthodes de récolte et de conservation. A ce point de vue, il serait bon de faire d'autres études pour quantifier la relation entre le climat et le potentiel de séchage du foin dans chacune des zones. Par ailleurs, dans l'application de ce système de zonage il faut tenir compte de la variation du taux de séchage pour les diverses espèces cultivées.

On présente à la figure 9 une carte de zonage en fonction du déficit en eau. Les variations du déficit en eau et de la valeur de la P.E.P.A. dans chacune des cinq zones de cette figure sont présentées au tableau 9 . Les zones sont délimitées par des intervalles de $25 \mathrm{~mm}$ de déficit en eau pour les sols ayant une C.R.S. de $100 \mathrm{~mm}$. On donne aussi la valeur du déficit en eau dans les sols de C.R.S. de $50 \mathrm{~mm}$ et $200 \mathrm{~mm}$.

On peut voir au tableau 9 que dans les zones W4 et W5, le déficit en eau peut être considérable pour les plantes cultivées dans des sols de C.R.S. de moins de $100 \mathrm{~mm}$. Par contre, dans les zones Wl et $W 2$, les risques de pénurie d'eau sont faibles durant les années normales, même pour les espèces à enracinement peu profond comme la fléole.

D'après la figure 9 , dans des conditions semblables (c.-à-d. C.R.S. et drainage), les cultures fourragères qui risquent le plus de souffrir d'une pénurie d'eau se trouvent dans la vallée inférieure de la rivière saint-Jean, dans l'est du Nouveau-Brunswick, dans la vallée d'Annapolis et dans une partie de la côte nord de la Nouvelle-f́cosse. Par contre, étant donné la nature des sols dans ces régions, c'est là qu'il est le moins probable que l'engorgement du sol, le lessivage des éléments nutritifs ou la dénitrification cause des problèmes durant l'été.

Tableau 9 Variation de la perte d'eau potentielle accumulée (P.E.P.A.) et du déficit en eau dans les zones de la figure 9

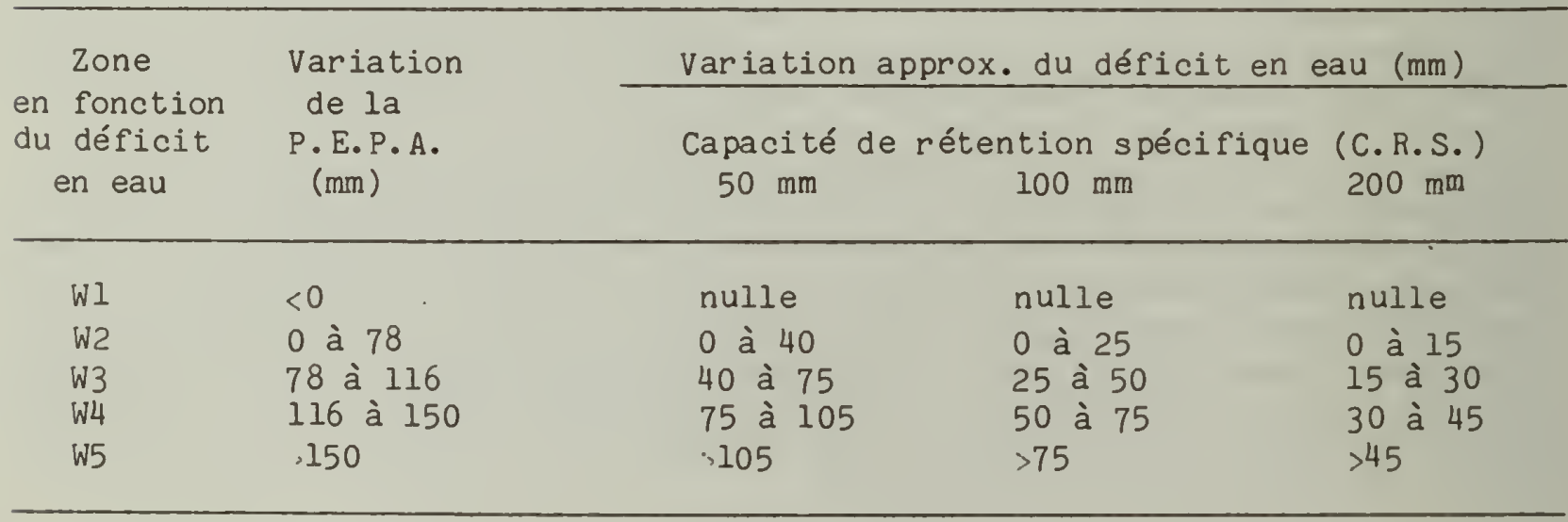




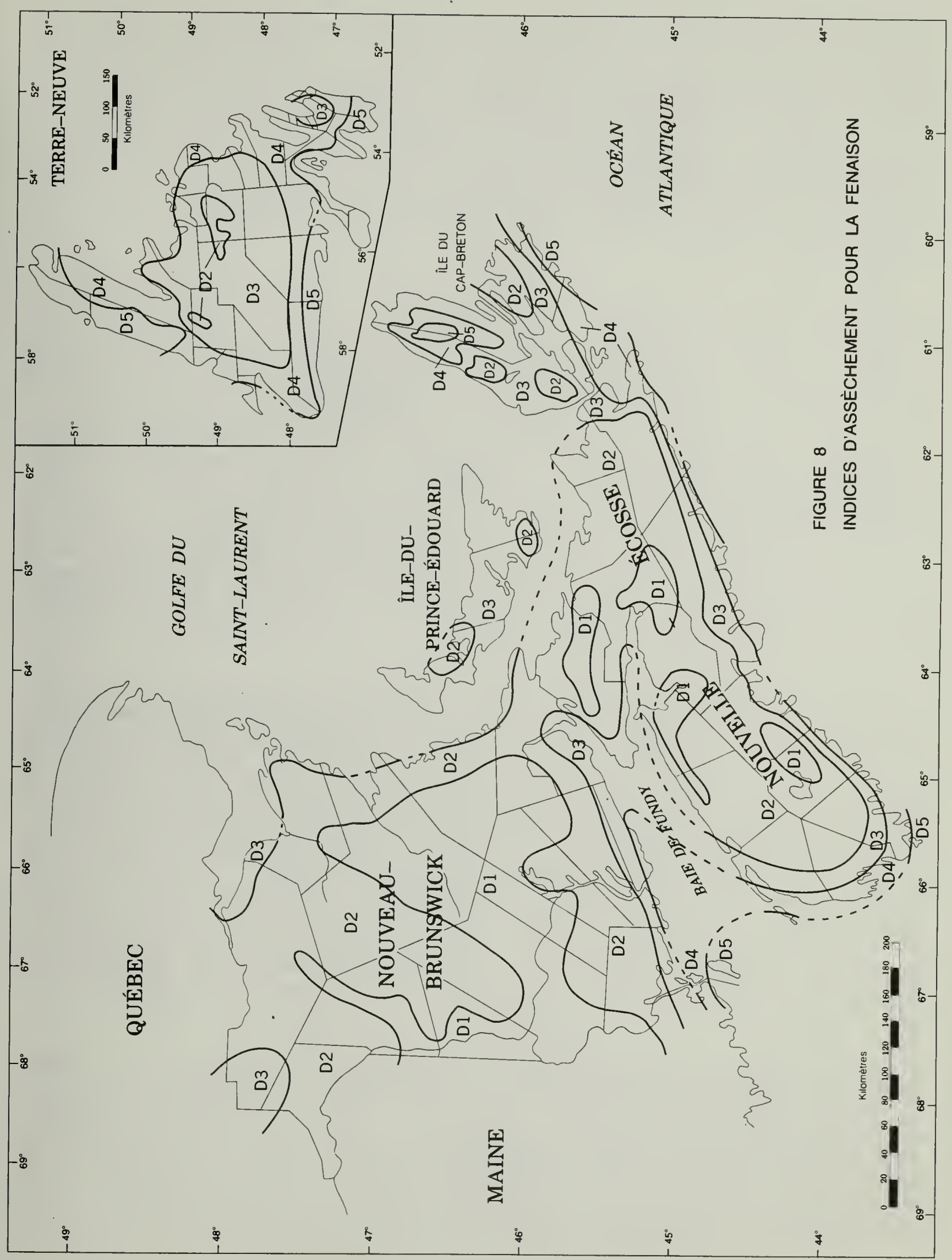


C'est dans les zones W1 et W2 que les $r$ isques de pénurie d'eau grave sont les moins élevés, mais c'est là par contre que les probabilités sont les plus fortes qu'il y ait un excès d'humidité par suite duquel le lessivage et la dénitrification pourraient être excessifs. Au Nouveau-Brunswick, les zones Wl et W2 comprennent la région de l'extrême nord-ouest et la côte sud longeant la baie de Fundy. En Nouvelle-Écosse, ces zones se limitent essentiellement à certaines régions des côtes sud et ouest et dans l'île-du-cap-Breton. La plus grande partie de Terre-Neuve se trouve dans les zones Wl et W2, à l exception de quelques régions isolées. Dans la zone Wl, la valeur de la P.E.P.A. est inférieure à 0 , ce qui indique que les pluies dépassent la valeur du facteur $\mathrm{EP}$ même durant l 'été.

Il est utile de comparer le déficit en eau estimé selon la méthode de Thornthwaite avec les besoins en irrigation ou le déficit en eau établis par Coligado et coll. (1968) au moyen d'un bilan hydrique quotidien, selon la méthode de Baier et Russelo (1968). Le déficit moyen que nous avons calculé pour des sols de C.R.S. de $200 \mathrm{~mm}$ était comparable à celui que coligado et coll. (1968) ont obtenu pour une capacité d'emmagasinement de $100 \mathrm{~mm}$

( 4 pouces), un facteur de consommation totale (C.T.) se situant entre 1,0 et 0,75 et un niveau de risque de $50 \%$. Le déficit en eau pour les sols de C.R.S. de $100 \mathrm{~mm}$ était semblable à celui que coligado a déterminé pour une capacité d'emmagasinement de $50 \mathrm{~mm}$ (2 pouces) et un facteur C.T. de 0,75. La valeur du déficit en eau pour les sols de C.R.S. de $50 \mathrm{~mm}$ était comparable à celle que Coligado a obtenue pour une capacité d'emmagasinement de $25 \mathrm{~mm}$ (l pouce) et un facteur C.T. se situant entre 0,75 et 0,5 . Comme la capacité d'emmagasinement employée par Coligado et coll. (1968) équivaut à 50\% de la C.R.S. appliquée dans notre étude, les valeurs du déficit en eau déterminées selon ces deux méthodes sont remarquablement semblables.

Sly et Coligado (1974) ont mis au point une méthode simple pour calculer le déficit en eau saisonnier; elle a servie à la préparation des cartes agroclimatiques du Canada. Par la suite, un système de classification des conditions climatologiques des sols d'après le déficit en eau saisonnier a été mis au point (Baier et Mack, 1973; Clayton et coll., 1977; Mack, 1970). Au tableau 10, nous avons comparé les zones que nous avons délimitées d'après le déficit en eau avec les sous-classes établies en fonction de l'humidité sur cette carte; ainsi, nous avons pu faire le lien entre nos résultats et un système de classification accepté à l'échelle nationale. Cette comparaison nous a aussi permis de mettre en rapport les valeurs du déficit en eau déterminées selon la méthode de Thornthwaite avec la classification canadienne des conditions climatologiques des sols de la région de l'Atlantique. Le tableau 10 contient en outre la description qualitative des conditions de pénurie d'eau que la fléole et la luzerne risqueraient de subir dans chacune des zones.

Pour calculer le taux d'irrigation ou le déficit en eau, sly et coligado (1974) ont supposé que lorsque, sur la totalité de l'eau retenue dans le sol, la portion facilement accessible ( $50 \%$ de la C.R.S.) est épuisée, le surplus d'eau nécessaire est apporté par irrigation. Comme les plantes fourragères sont cultivées dans des champs non irrigués dans la région de l'Atlantique, la méthode de Thornthwaite nous a semblé plus appropriée pour notre étude. Nous avons employé les données d'un plus grand nombre de stations météorologiques dans la région; ces données couvraient la période normale de 30 ans la plus 


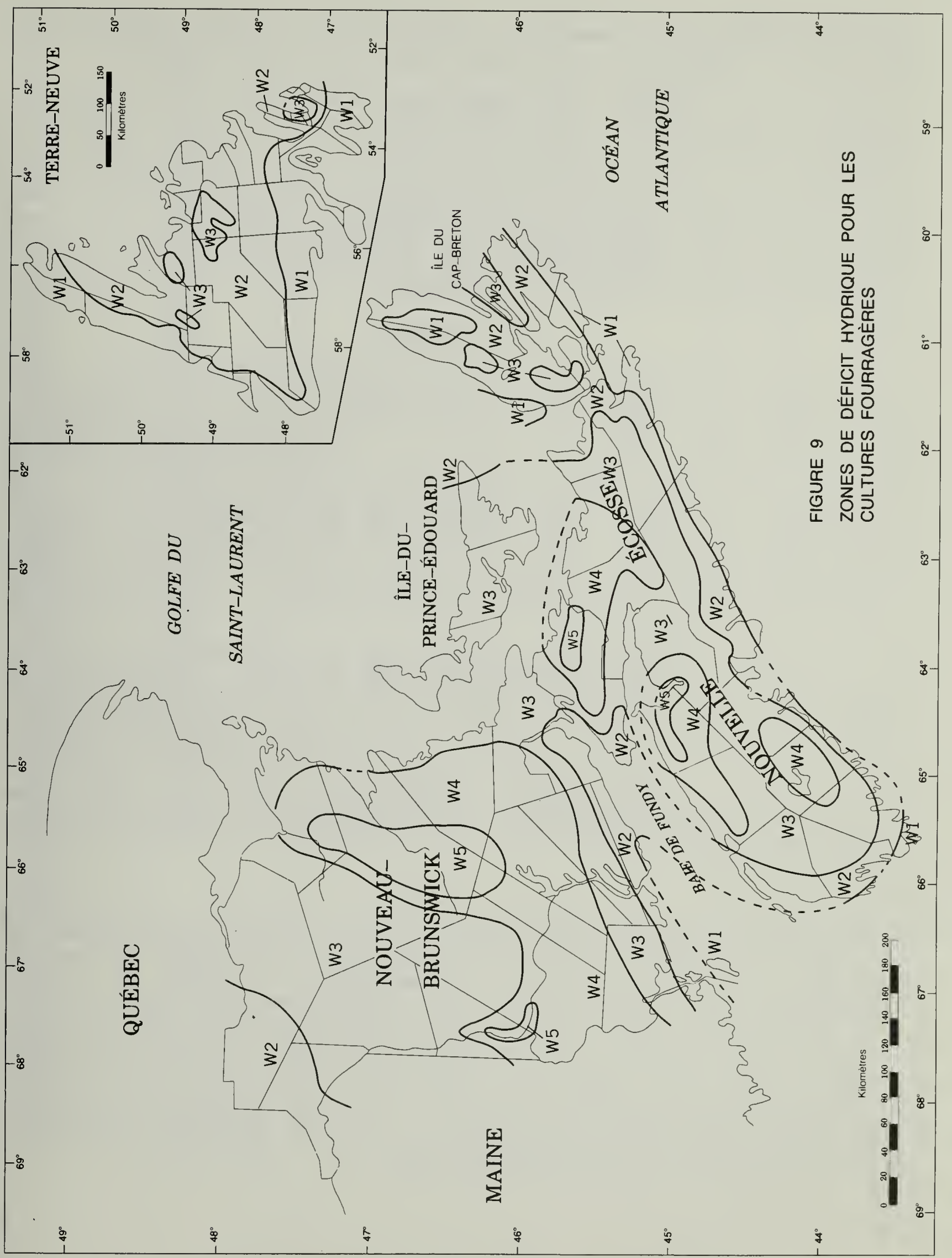


récente. Même si les méthodes et les périodes analysées diffèrent, nos résultats semblent relativement bien concorder avec ceux des études de zonage en fonction du déficit et eau réalisées antérieurement dans la région.

Nous ignorons encore dans quelle mesure le déficit en eau limite le rendement des cultures fourragères dans chaque zone. Il faudrait continuer la recherche pour connaitre cette relation; ce faisant, on faciliterait l'évaluation de la productivité potentielle des terres pour diverses plantes fourragères et l'estimation de leur rendement en fonction de l'irrigation. Pour se servir des systèmes de zonage basés sur le déficit en eau, il faut tenir compte des variations dans les caractéristiques propres à diverses espèces de plantes fourragères comme la consommation d'eau, la résistance à $l$ 'assèchement et la résistance à l'engorgement.

\section{CONCLUSION}

Les résultats de nos analyses climatologiques devraient se révéler utiles pour formuler des recommandations plus précises au sujet de la production et de la régie des plantes fourragères dans la région de l'Atlantique. Cependant, il faut aussi tenir compte de l'expérience pratique dans les diverses parties de la région. Les zones ont été délimitées à une échelle qui ne rend pas compte des variations de la réaction des cultures aux microclimats. De même, nous n'avons pas tenu compte des variations climatiques d'une année à l'autre qui influent sur la production et la régie des plantes fourragères. Notons aussi que la transition entre les zones délimitées sur les cartes est habituellement graduelle, et non abrupte comme on pourrait le conclure en observant les cartes.

Nos critères et interprétations sur la régie et la production des plantes fourragères devront être améliorés et ajustés au fur et à mesure que les futurs travaux de recherche et essais sur le terrain nous apporteront de nouvelles données et que les ressources climatiques actuelles de la région seront mieux définies. Par ailleurs, il ne faudrait pas interpréter nos résultats comme une indication que les espèces et cultivars mentionnés dans le présent rapport sont bien adaptés à toutes les zones de la région. Nos conclusions concernent plutôt les mesures culturales recommandées lorsque l'expérience dans un terrain donné a montré qu'il est possible d'y produire certains cultivars.

Nous avons décrit des méthodes de calcul simples basées sur des normales météorologiques mensuelles pour déterminer les critères climatologiques qui ont servi au zonage. Ces méthodes facilitent l'emploi des données des stations météorologiques dont les normales, qui couvrent une période relativement courte, ont été ajustées pour correspondre à la période normale de 30 ans la plus récente. De plus, ces méthodes simplifient les calculs pour d'autres périodes normales, si la chose était nécessaire. Nous avons signalé plusieurs domaines où d'autres recherches seraient nécessaires. Les cartes de zonage devraient être utiles pour choisir les emplacements propices à la réalisation d'expériences sur le terrain. Enfin, nos résultats présentent un certain intérêt en matière d'évaluation des terres, spécialement s'ils sont intégrés aux données sur les sols de la région. 


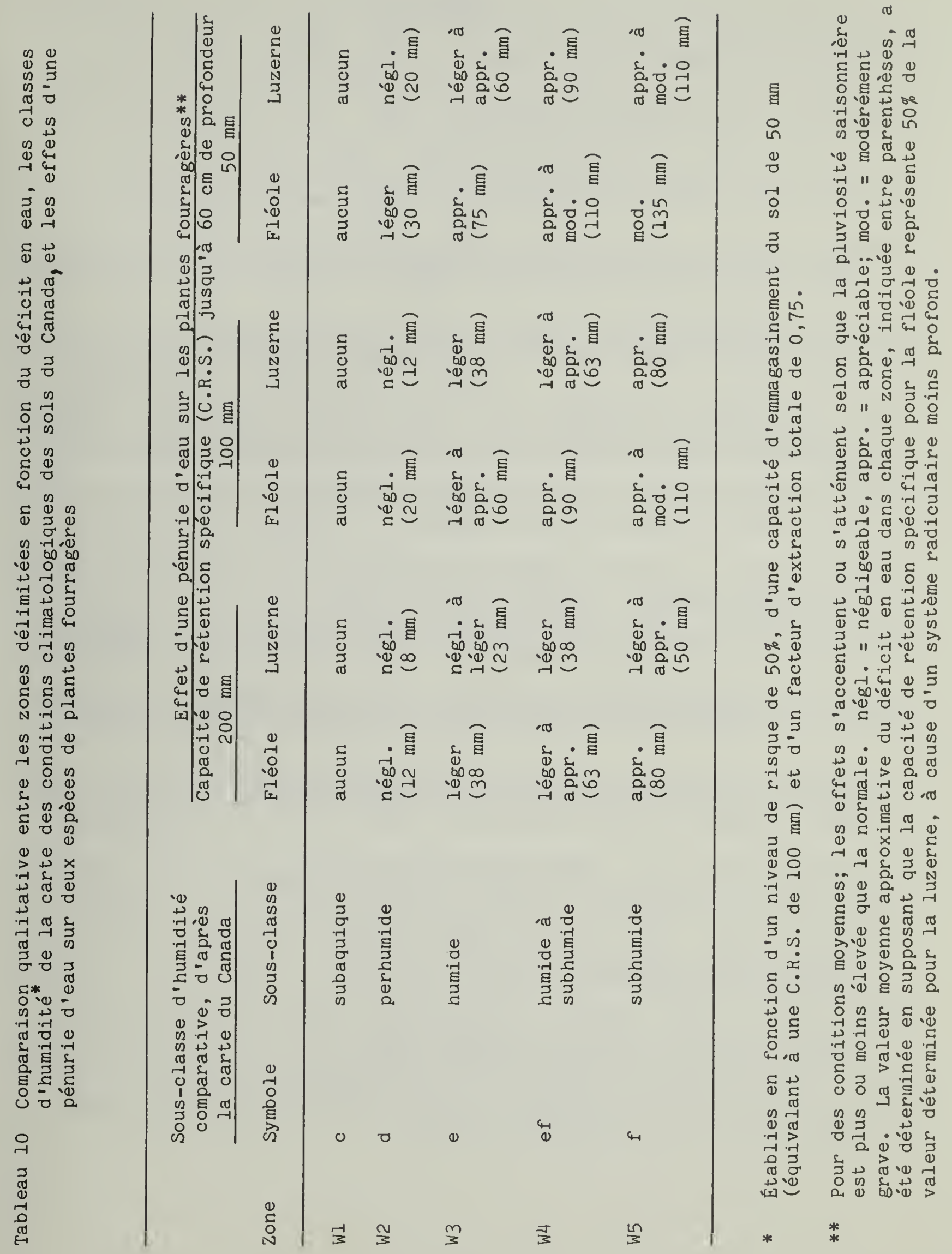




\section{REFERENCES}

Atlantic Field Crops Committee (A.F.C.C.). 1975. Report of field trials conducted in 1975. Forage Sub-Comm. Report. p. G-6.

Atlantic Field Crops Committee (A.F.C.C.). 1980. Field crop guide, Atlantic provinces. A.F.C.C. Publ. 100, Agdex 100, pp. 33-45.

Baier, W. 1971. Evaluation of latent evaporation estimates and their conversion to potential evaporation. Can. J. Plant Sci. 5l: 255-266.

Baier, W. and Mack, A.R. 1973. Development of soil temperature and soil water criteria for characterizing soil climates in canada. In: Field soil Water Regimes, special publ. No. 5, Soil Sci. Soc. Amer., pp. 195-2l2.

Baier, W. and Robertson, G.W. 1965. Estimation of latent evaporation from simple weather observations. Can. J. Plant Sci. 45: 276-284.

Baier, W. and Russelo, D.A. 1968. A computer program for estimating risks of irrigation requirements from climatic data. Tech. Bull. No. 59, Agrometeorol. Sect., Plant Res. Inst., Can. Dept. Agric., Ottawa, 48 pp.

Black, W.N. 1978. Effects of irrigation and nitrogen on a natural pasture sward. Can. J. Plant Sci. 58: 347-356.

Bootsma, A. 1976. A note on minimum temperature and the climatological day at first order stations. Atmosphere 14(1): 53-55.

Calder, F.W. and Nicholson, J.W.G. 1970. Pasture productivity of three swards with and without nitrogen fertilizer. Can. J. Anim. Sci. 50: 467-473.

Clayton, J.S., Ehrlich, W.A., Cann, D.B., Day, J.H. and Marshall, I.B. 1977. Soils of Canada, Vol. 1: Soil Report. pp. 73-77.

Coligado, M.C., Baier, W. and Sly, W.K. 1968. Risk analyses of weekly climatic data for agricultural and irrigation planning. Tech. Bull. Nos . 17-24, Agrometeorol. Sect., Plant Res. Inst., Can. Dep. Agric.,34 pp.

Environment Canada. 1971. Temperature and precipitation 1941-1970, Atlantic provinces. Atmospheric Environment Service, Downsview, Ont., 55 pp.

Environment Canada. 1982. Canadian climate normals: temperature and precipitation 1951-1980, Atlantic provinces. Atmospheric Environment Service, Downsview, Ont., $136 \mathrm{pp}$.

Fulkerson, R.S. 1970. Location and fall harvest effects in ontario on food reserve storage in alfalfa (Medicago sativa L.). In: Proceedings of the XI International.Grassland Congress, Univ. Queensland Press, pp. 555-559.

Fulkerson, R.S. 1974. Stop alfalfa winterkill. Ontario Min. Agric. Food, Factsheet No. 74-040, Agdex 121/21, 2 pp. 
Fulkerson, R.S. 1982. Fall harvest effects on the yield and persistence of birdsfoot trefoil (Lotus corniculatus L.). Forage Notes 26(1): 12-13.

Gottfred, N. 1980. Winter survival of forage stands. Manitoba Agriculture, Forage Facts, Agdex 120/21, 3 pp.

Grant, E.A. and Burgess, P.L. 1978. Timothy: High-quality forage for livestock in Eastern Canada. Agriculture Canada publ. 1640, 15 pp.

Hayhoe, H.N. and Jackson, L.P. 1974. Weather effects on hay drying rates. Can. J. Plant Sci. 54: 479-484.

Heinrichs, D.H. 1969. Alfalfa in Canada. Canada Dept. Agric. Publ. 1377, $28 \mathrm{pp}$.

Knight, W.E. and Hollowell, E.A. 1958. The influence of temperature and photoperiod on growth and flowering of crimson clover (Trifolium incarnatum L.). Agron. J. 50: 295-298.

Kozumplik, V. and Christie, B.R. 1972. Heading response of orchardgrass seedlings to photoperiod and temperature. Can. J. Plant Sci. 52: 369-373.

Kunelius, H.T. 1980. Effects of nitrogen rates and harvest schedules on yield and quality of Westerwolds ryegrass grown as a summer annual. Can. J. Plant Sci. 60: 519-524.

Kunelius, H.T., Suzuki, M. and Winter, K.A. 1976. Influence of harvest systems and nitrogen rates on yields, quality, and persistence of Champ timothy in the seeding and postseeding years. Can. J. Plant Sci. 56: $715-723$.

Kunelius, H.T. and Suzuki, M. 1977a. Seeding year yields and quality of orchardgrass as influenced by $\mathrm{N}$ rates and harvest systems. Can. J. Plant Sci. 57: 427-431.

Kunelius, H.T. and Suzuki, M. 1977b. Response of orchardgrass to multiple harvests and rates of nitrogen in post-seeding years. Can. J. Plant Sci. 57: 763-770.

Kunelius, H.T. and Calder, F.W. 1978. Effects of rates of $N$ and regrowth intervals on yields and quality of Italian ryegrass grown as a summer annual. Can. J. Plant Sci. 56: 69l-697.

Mack, A.R. 1970. Report of the subcommittee on soil climate in relation to soil classification and interpretation. In: Proceedings of the eighth meeting of the Canada Soil Survey Committee, Ottawa, Ont., pp. 2l-34.

MacKenzie, D.N. and Suzuki, M. 1978. Winter survival of forage legumes, winter cereals and strawberries in the Maritime provinces in 1978. 1978 Research Summary, Agric. Can. Res. Sta., Charlottetown, p. 30-31. 
Macleod, L.B., Kunelius, H.T. and Calder, F.W. 1972. Effects of early summer and fall cutting management on dry matter yields, digestibility, crude protein, and survival of Saranac and Narragansett alfalfas. Can. J. Plant Sci. 52: 941-948.

Ontario Field Crops Research Committee (O.F.C.R.C.). 1981. 1981 Field crop recommendations. Ont. Min. Agric. Food, Publ. 296, p. 10.

Pearson, C.J. and Hunt, L.A. 1972. Effects of temperature on primary growth of alfalfa. Can. J. Plant Sci. 52: 1007-1015.

Phillips, D.W. 1976. Monthly water balance tabulations for climatological stations in Canada. Environment Canada, Atmospheric Environment, DS No. 4-76 (Revised).

Robertson, G.W. and Russelo, D.A. 1968. Astrometeorological estimator for estimating time when sun is at any elevation, elapsed time between the same elevations in the morning and afternoon, and hourly and daily values of solar energy, Qo. Tech. Bull. 14, Agrometeorol. Sect., Research Branch, Agriculture Canada, Ottawa, $22 \mathrm{pp}$.

Selirio, I.S. and Brown, D.M. 1979. Soil moisture-based simulation of forage yield. Agric. Meteorol. 20: 99-114.

Sly, W.K. and Coligado, M.C. 1974. Agroclimatic maps for Canada - derived data: Moisture and temperature regimes. Tech. Bull. No. 81, Agrometeorol. Sect., Plant Res. Inst., Agric. Canada, Ottawa, 36 pp.

Smith, D. and Jewiss, O.R. 1966. Effects of temperature and nitrogen supply on the growth of timothy (Phleum pratense L.). Ann. Appl. Biol. 58: 145-157.

Suzuki, M. and McRae, K.B. 1979. Factors influencing winter survival of forage legumes in the Maritime provinces. 1979 Research Summary, Agric. Can. Res. Sta., Charlottetown, p. 32.

Thom, H.C.S. 1966. Normal degree days above any base by the universal truncation coefficient. Monthly Weather Review 94(7): 461-465.

Thornthwaite, C.W. 1948. An approach towards a rational classification of climate. Geographical Review 38(1): 55-94.

Thornthwaite, C.W. and Mather, J.R. 1957. Instructions and tables for computing potential evapotranspiration and the water balance. Drexel Inst. Tech., Centerton, N.J., Publ. Climatol. 10(3): 181-3ll.

Treidl, R.A. (ed.) 1978. Handbook on agricultural and forest meteorology, Part I. Atmospheric Environment Service, Downsview, Ont., Table 3.

Treidl, R.A. (ed.) 1979. Handbook on agricultural and forest meteorology, Part II. Atmospheric Environment Service, Downsview, Ont., Table 5. 
Wilkinson, J.M. 1981. Losses in the conservation and utilization of grass and forage crops. Ann. Appl. Biol. 98: 365-375.

Willis, C.B. and Suzuki, M. 1971. Effect of cutting management on forage yield, carbohydrate reserves and root vitality of alfalfa. 1971 Research Summary, Agric. Can. Res. Sta., Charlottetown, pp. 2l-22.

Woolley, D.G. and Wilsie, C.P. 1961. Cold unit accumulation and cold hardiness of alfalfa. Crop Sci. 1: 165-167. 


\section{ANNEXE}

Des données climatologiques provenant de 232 stations, situées dans la région de l'Atlantique et énumérées au tableau 11, ont servi à l'étude du zonage des cultures fourragères. Une carte montrant l'emplacement approximatif de chacune des stations climatologiques (fig. 10) est jointe au présent annexe. On énumère au tableau 11 les paramètres mesurés dans ces stations. Voici une brève description de ces paramètres.

$\underline{N^{\circ}}$ de colonne

1. Numéro de la station. Ces numéros sont attribués selon l 'ordre alphabétique des stations de chaque province. Ce sont les mêmes qu'à la figure 10.

2. Nom de la station. Le nom des stations est tiré des publications d'Environnement Canada sur les normales de la période allant de 1951 à 1980 (1982). Lorsque plus d'une station ont reçu le même nom, on précise l'élévation entre parenthèses.

3. Type de normale. Le code indiquant la durée de la période d'enregistrement est basé sur les normales de température et de précipitations publiées pour la période de 1951 à 1980 par Environnement Canada (1982). Lorsque la période normale de ces deux variables diffère, on indique d'abord le code de la température, puis celui des précipitations, par ex. 1/2. Les codes correspondent aux périodes suivantes:

\section{Code}

1 période de 30 ans complète

2 de 25 à 29 ans

3 de 22 à 24 ans

8 valeurs normales ajustées couvrant une période de 5 à 19 ans entre 1951 et 1980 et toutes autres données datant de 1931 à 1950 .

Les stations synoptiques de premier ordre ol l'on fait des observations horaires sont marquées d'un astérisque (*) placé à côté du type de normale considéré. Toutes les données dérivées de la température provenant de ces stations peuvent être faussées à cause de décalage de la journée climatologique pour la température minimum, par rapport aux stations météorologiques ordinaires.

4. Date des 450 D.J.C. au printemps. Date moyenne à laquelle 450 degrés-jours de croissance au-dessus de $5^{\circ} \mathrm{C}$ se sont accumulés au printemps; on la détermine au moyen de l'équation de régression (2) à laquelle on applique la température ambiante moyenne des mois de mai et juin pour la période normale de 1951 à 1980. La date des 350 D.J.C. tombe généralement environ 10 jours plus tôt.

5. Date des 450 D.J.C. en automne. Date moyenne à laquelle il reste 450 degrés-jours de croissance au-dessus de $5^{\circ} \mathrm{C}$ en automne; on l'estime au moyen des équations de régression (4) et (6) auxquelles on applique la température ambiante moyenne de septembre et d'octobre pour la période normale de 1951 à 1980 . 


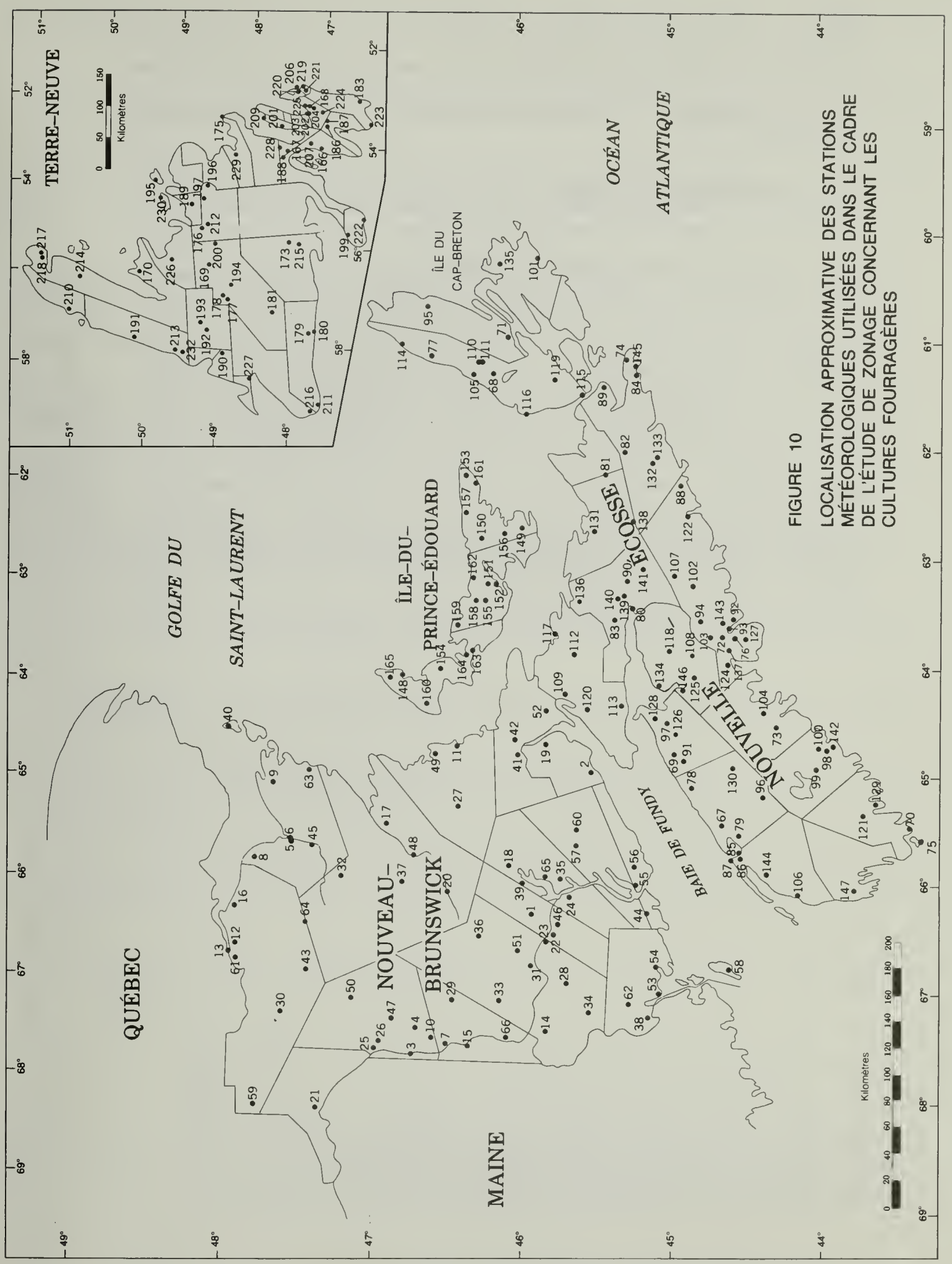


6. Jours. Indice représentant la longueur de la saison de croissance qu'on détermine d'après l'intervalle entre la date où 350 D.J.C. se sont accumulés au printemps et celle où il reste 450 D.J.C. en autome.

7. Indice de séchage. Sa valeur, exprimée en $\mathrm{mm}$, est déterminée au moyen de I'équation (7).

8. Indice de séchage normalisé. Les valeurs de cette colonne sont déterminées au moyen de l'équation (12). Cet indice étant "normalisé", il est exprimé sans unité. Dans quelques cas, sa valeur peut dépasser 100.

9. E.P. On estime l'évaporation potentielle, exprimée en $\mathrm{mm}$, des mois de juin à août par la méthode de Baier et Robertson (équations (8) et (11)).

10. Précip. Valeur moyenne des précipitations totales ( $P$ ), exprimée en mm, des mois de juin à août pour la période normale de 1951 à 1980 .

11. P.E.P.A. On détermine la valeur de la perte d'eau potentielle accumulée des mois de juin à aout en appliquant la formule P.E.P.A. = EP - P.

12. Déficit en eau. Les déficits moyens en eau ( $\mathrm{mm}$ ) dans des sols de capacité de rétention spécifique de 50,100 et $200 \mathrm{~mm}$ sont calculés à partir des valeurs de P.E.P.A. en utilisant les équations du tableau 2. Dans le présent document, la capacité de rétention spécifique du sol est la quantité d'eau présente dans un sol entre le point de saturation et le point de flétrissement permanent. 
$\approx$ 这品

$\Rightarrow \quad$ 通

일

a

品睍

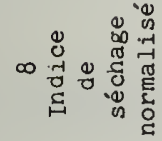

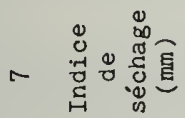

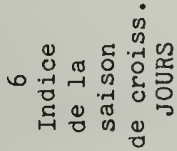
ขึํำ

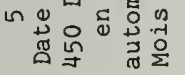
m $\quad \begin{aligned} & 0 \\ & 0\end{aligned}$

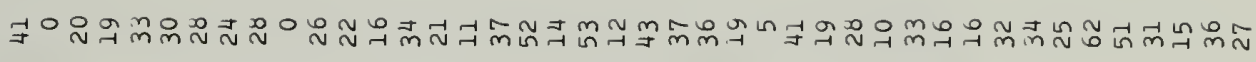

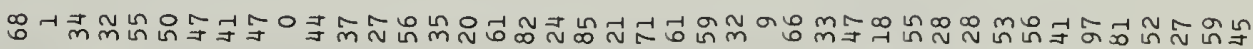

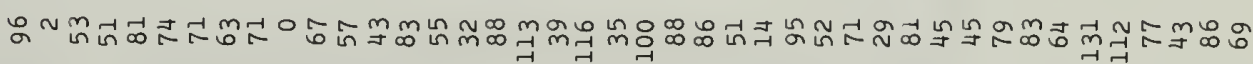

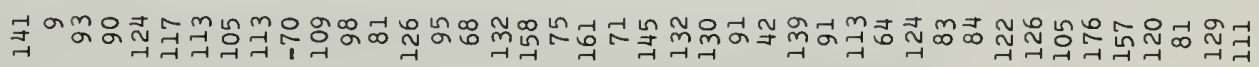

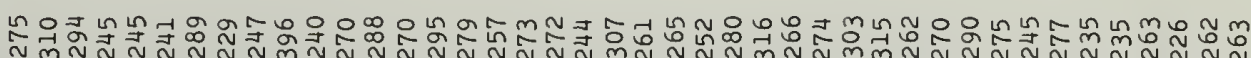

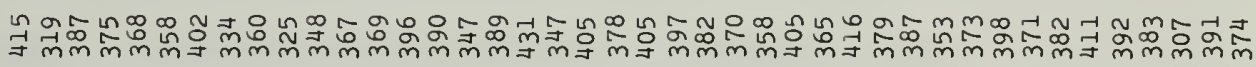

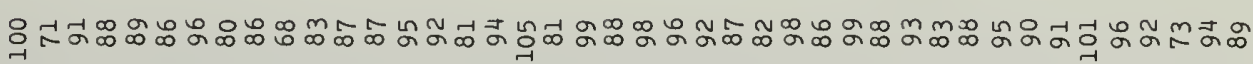

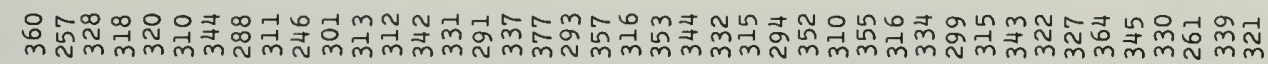

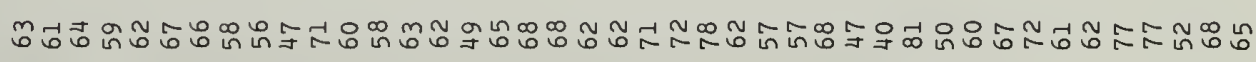

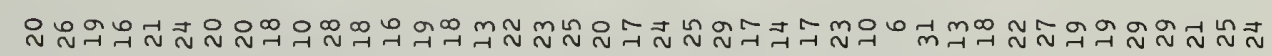

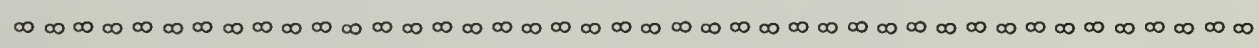

ล

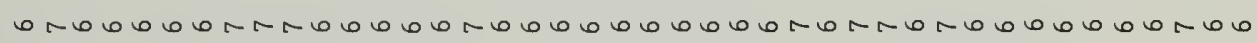

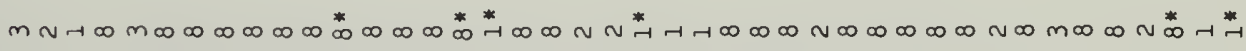

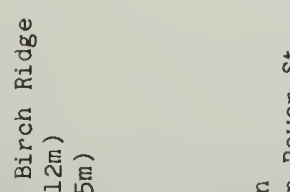
$\times$ 垔 


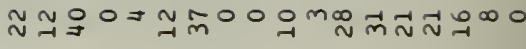

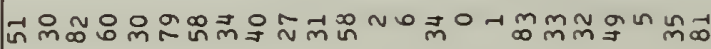

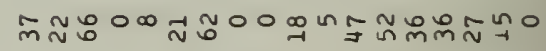

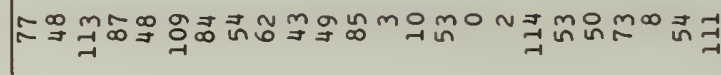

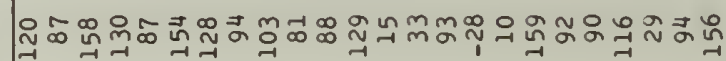

䓌自 $\rightarrow$

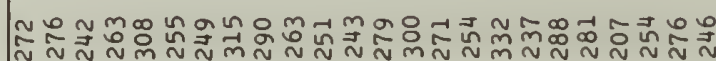

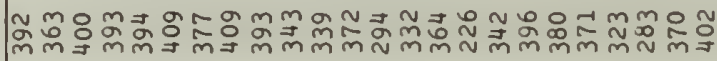

×

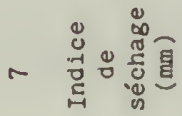

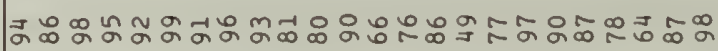

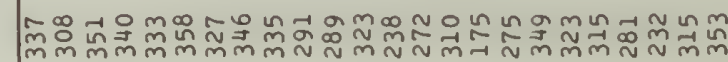

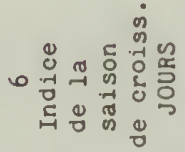

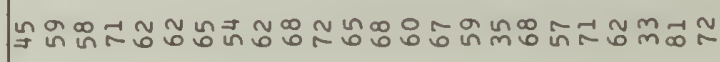

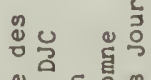

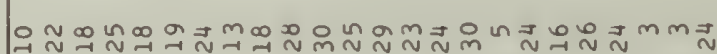

in $\infty \infty$

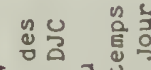

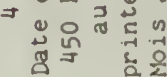

กm

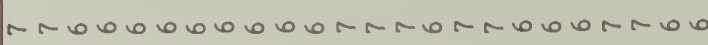

$\approx$

n

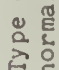

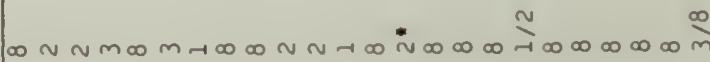

$\stackrel{\infty}{m}$

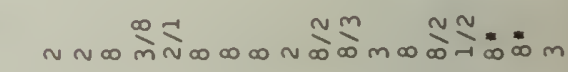

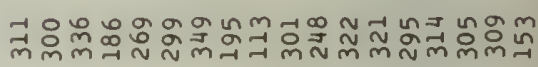

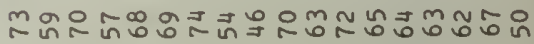

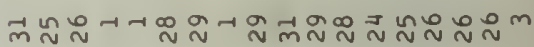
$\infty \infty \infty$ a $\infty \infty \propto \infty \infty \infty \infty \infty \infty \infty \infty$ a

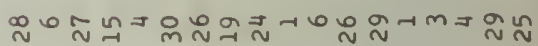
6ー

ร

3
0
0
0
0

के

$\stackrel{4}{\pi}$

잉

$\stackrel{8}{\frac{8}{2}}$

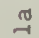

ำ

$z$ in 


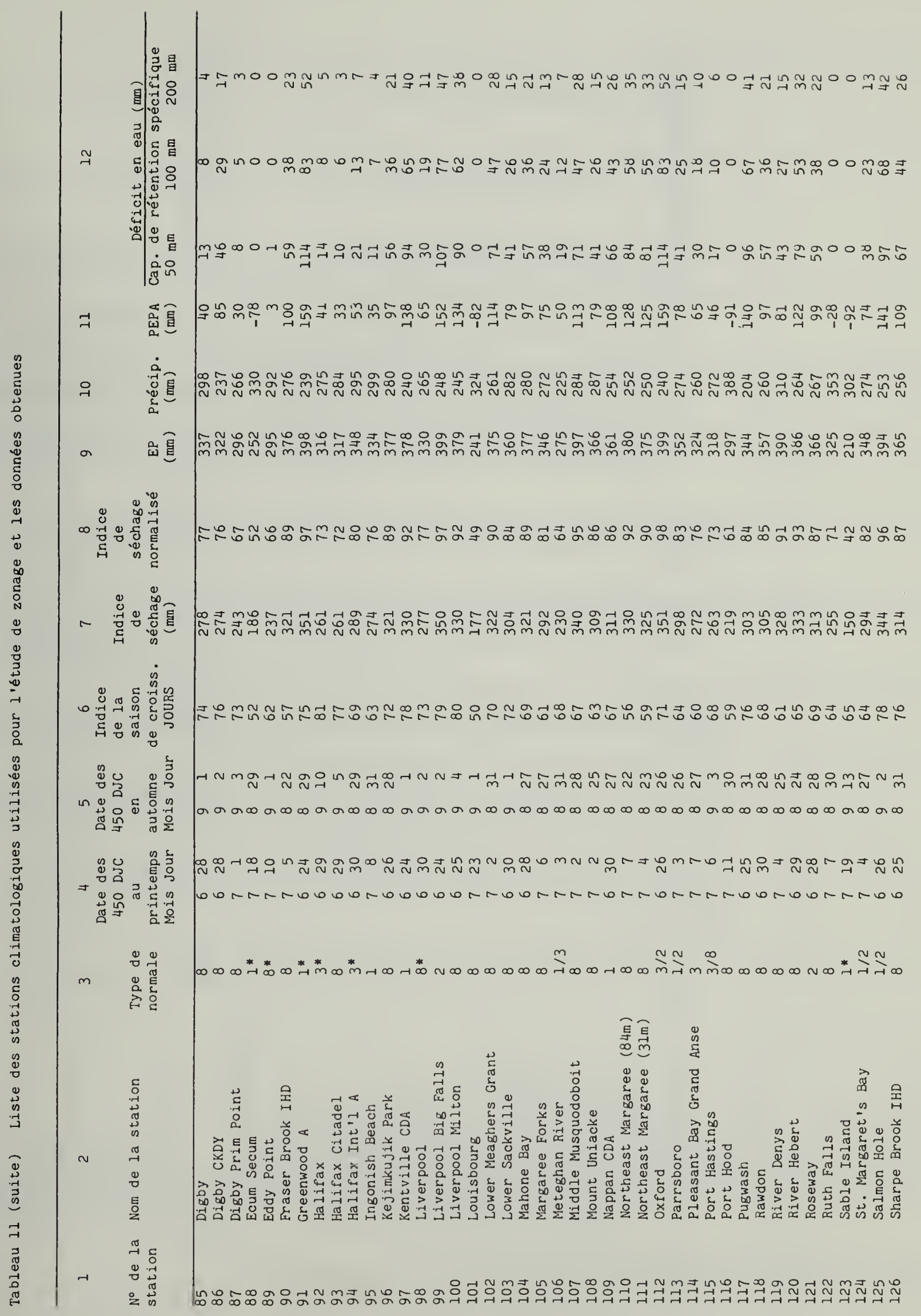




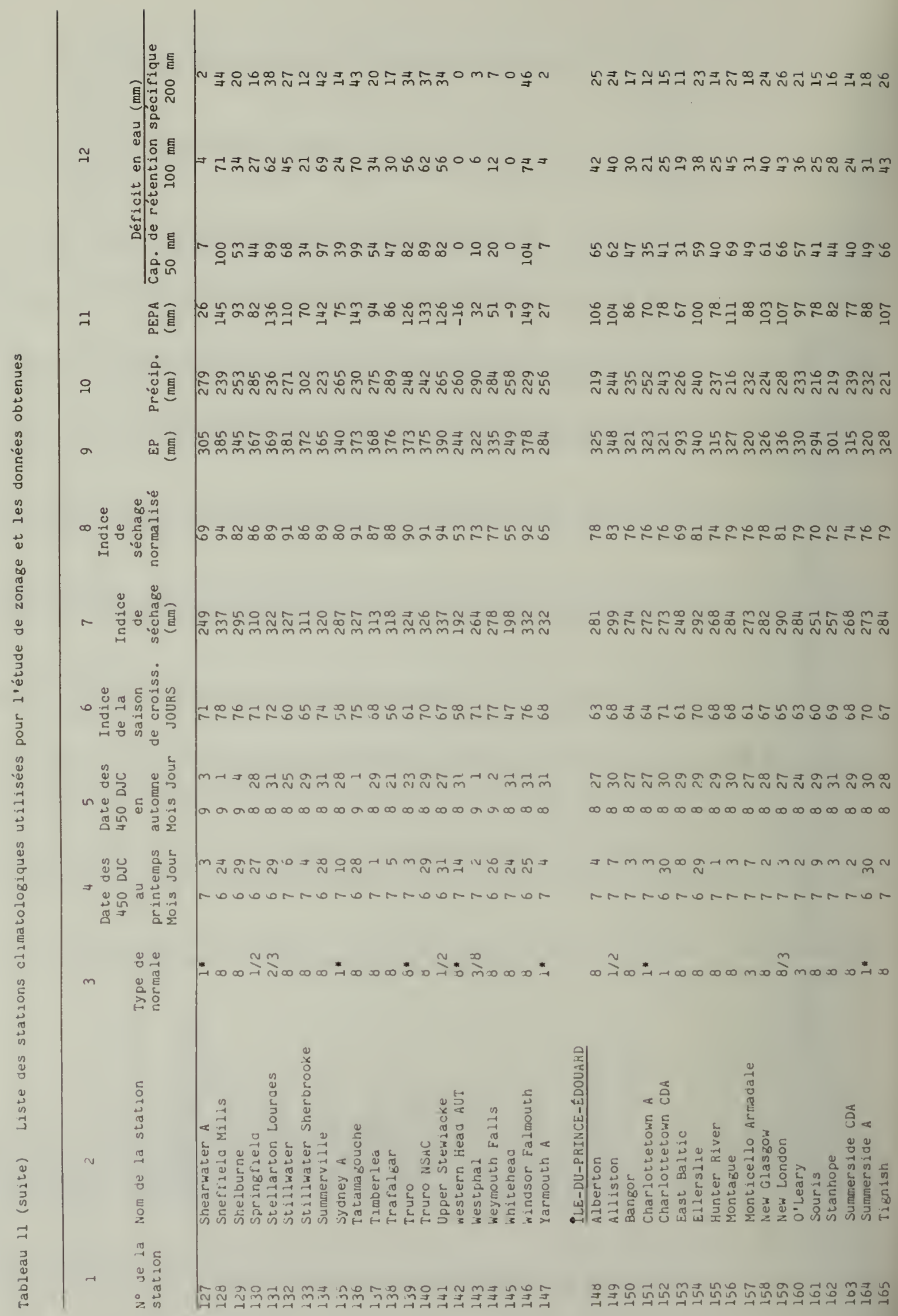




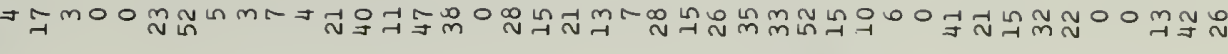

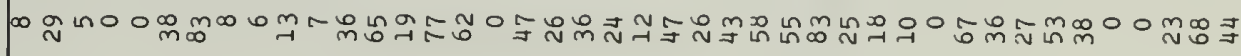

mర્త゙

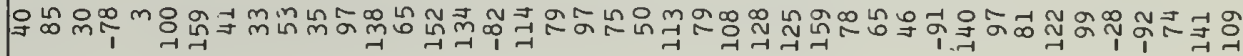

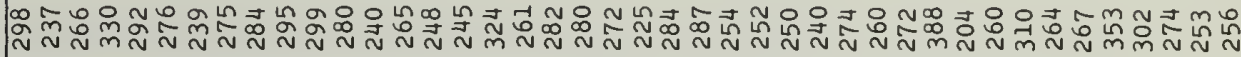

喿晴

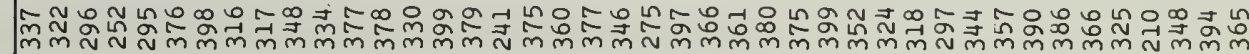

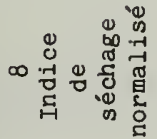

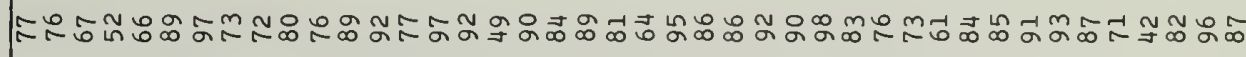

萡

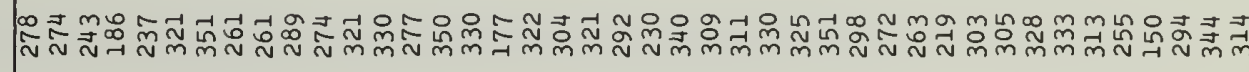

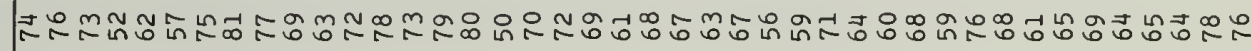

H N m N

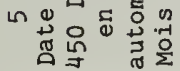

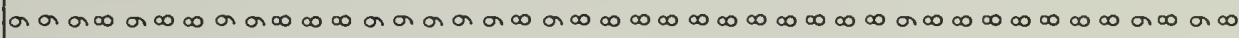

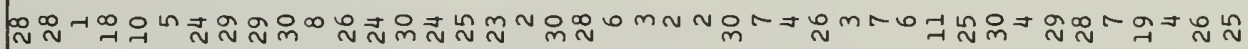

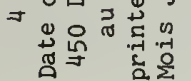

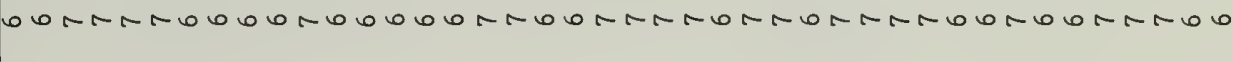
을

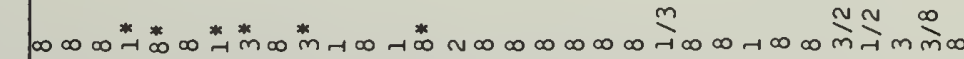

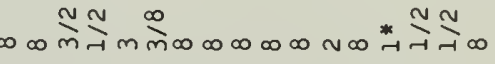

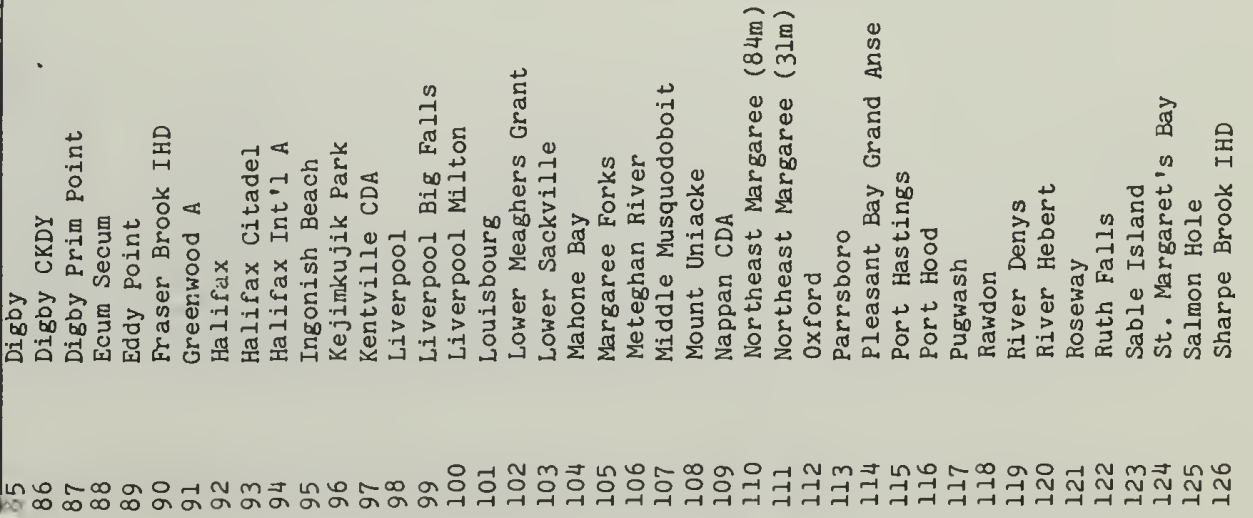




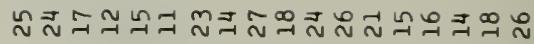

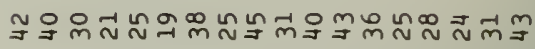

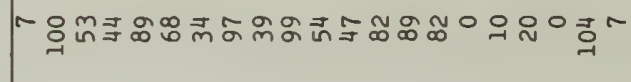

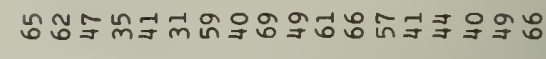

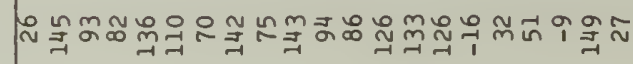

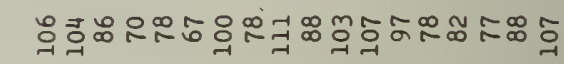

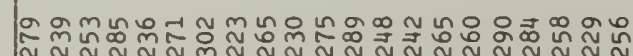

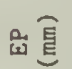

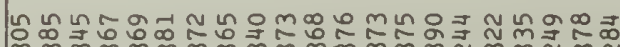

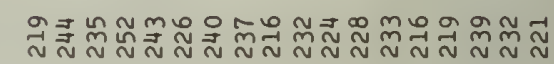

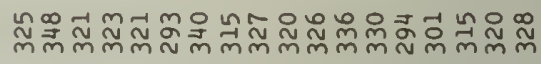
政

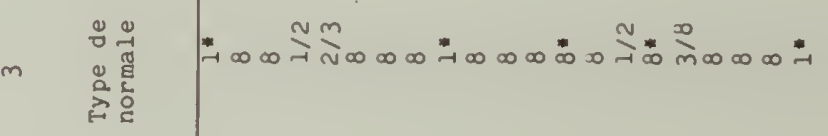

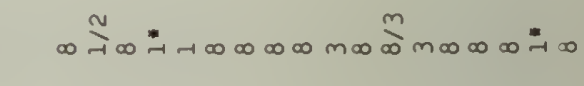

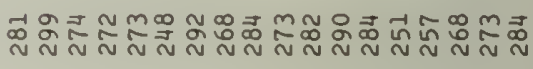

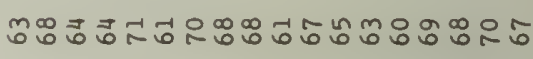
సัํำ $\infty \infty \infty \infty \infty \infty \infty \infty \infty \infty \infty \infty \infty \infty \infty \infty \infty \infty \infty \infty \infty \infty \infty \infty \infty \infty \infty)$

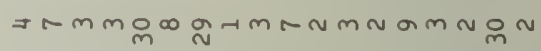

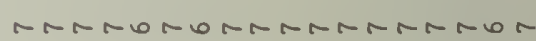

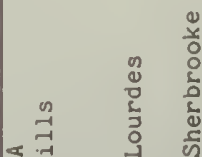

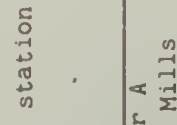




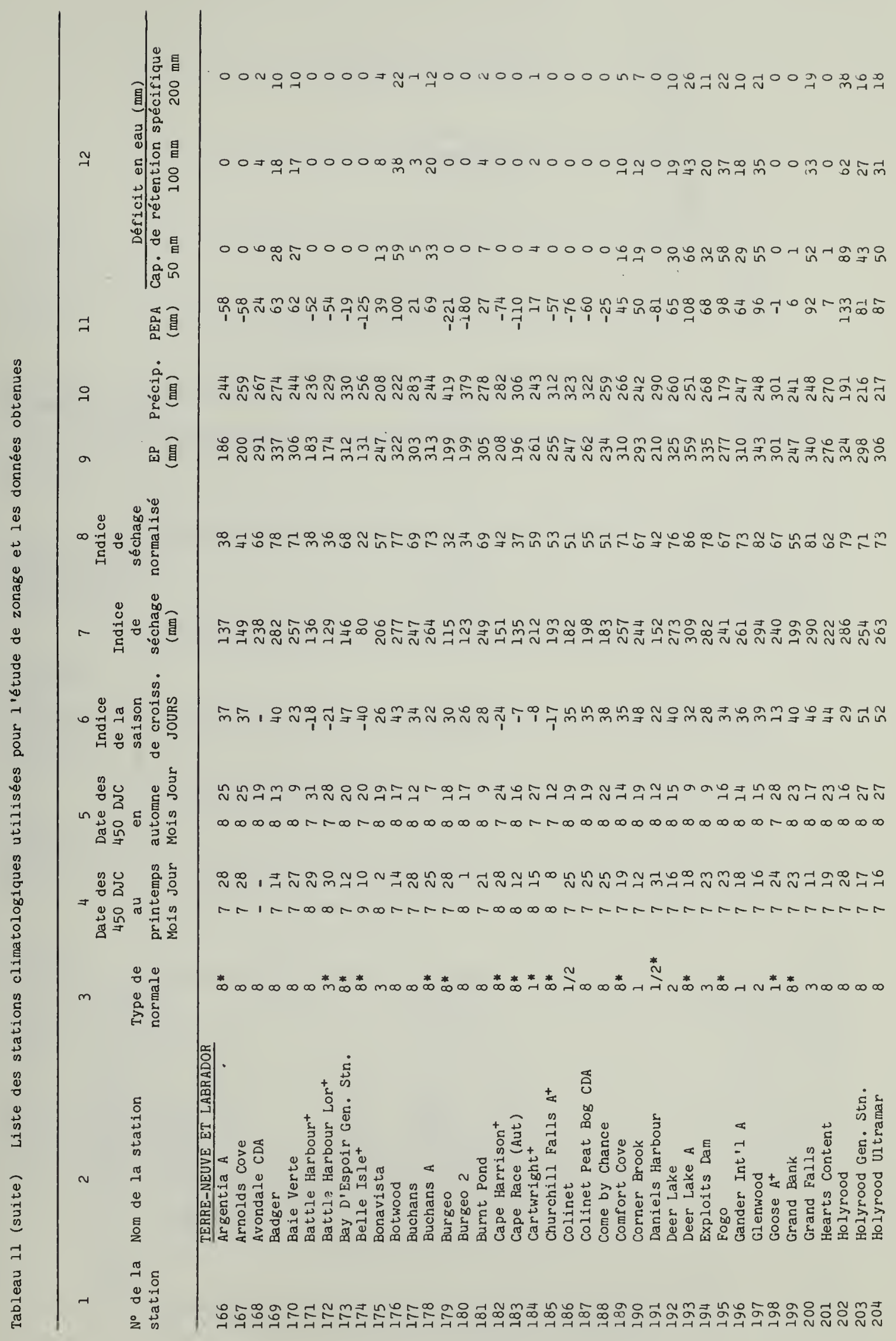




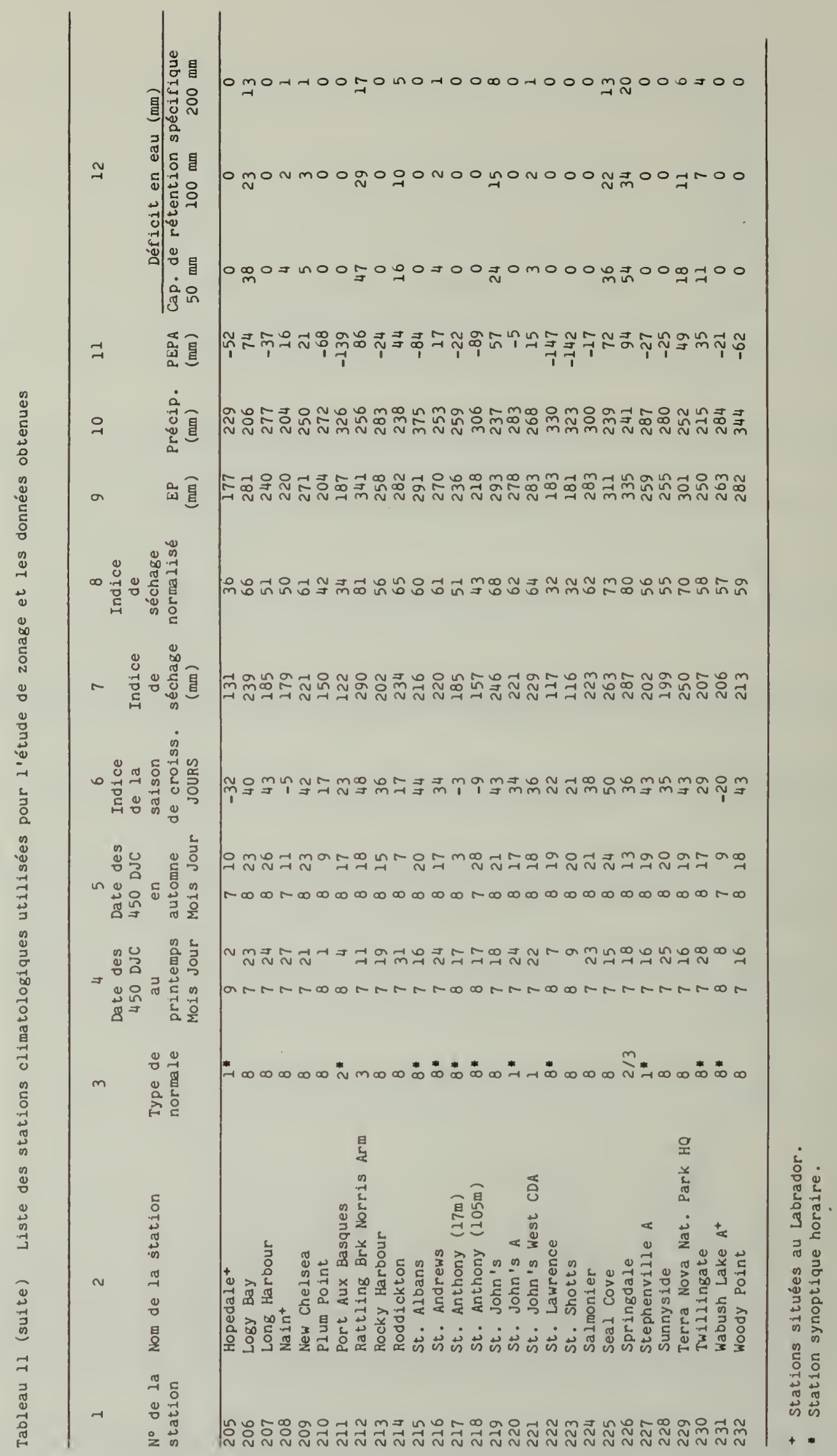


Unité métrique

\section{LINÉAIRE}

millimètre $(\mathrm{mm})$

centimètre $(\mathrm{cm})$

mètre $(\mathrm{m})$

kilomètre $(\mathrm{km})$

\section{SUPERFICIE}

centimètre carrè $\left(\mathrm{cm}^{2}\right)$

mètre carré $\left(\mathrm{m}^{2}\right)$

kilomètre carré $\left(\mathrm{km}^{2}\right)$

hectare (ha)

\section{VOLUME}

centimètre cube $\left(\mathrm{cm}^{3}\right)$

mètre cube $\left(\mathrm{m}^{3}\right)$

mètre cube $\left(\mathrm{m}^{3}\right)$

\section{CAPACITÉ}

litre (L)

hectolitre (hL)

hectolitre (hL)

\section{POIDS}

gramme (g)

kilogramme $(\mathrm{kg})$

tonne (t)

\section{AGRICOLE}

litres à l'hectare (L/ha) litres à l'hectare (L/ha) litres à l'hectare (L/ha)

millilitres à I'hectare (mL/ha)

tonnes à l'hectare (t/ha)

kilogrammes à l'hectare (kg/ha)

grammes à l'hectare $(g / h a)$

plants à l'hectare (plants/ha)
Facteur

approximatif

de conversion

Donne

$\times 0,04$

pouce

$\times 0,39$

pouce

$\times 3,28$

$\times 0,62$

pieds

mille

$$
\begin{aligned}
& \times 0.15 \\
& \times 1,2 \\
& \times 0.39 \\
& \times 2.5
\end{aligned}
$$

pouce carrè verges carrées mille carré acres

pouce cube pieds cubes verges cubes

pied cube gallons boisseaux

once

livres

tonnes courtes

gallons à l'acre pintes à l'acre chopines à l'acre onces liquides à

l'acre

tonnes à l'acre livres à l'acre onces à l'acre plants à l'acre 



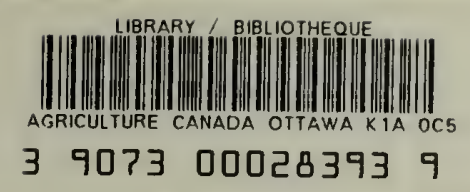


